\title{
FM1-43 Dye Behaves as a Permeant Blocker of the Hair-Cell Mechanotransducer Channel
}

\author{
J. E. Gale, ${ }^{1}$ W. Marcotti, ${ }^{1,2}$ H. J. Kennedy, ${ }^{2}$ C. J. Kros, ${ }^{1,2}$ and G. P. Richardson ${ }^{1}$ \\ 1School of Biological Sciences, University of Sussex, Falmer, Brighton, BN1 9QG, United Kingdom, and 2School of \\ Medical Sciences, University of Bristol, Bristol, BS8 1TD, United Kingdom
}

\begin{abstract}
Hair cells in mouse cochlear cultures are selectively labeled by brief exposure to FM1-43, a styryl dye used to study endocytosis and exocytosis. Real-time confocal microscopy indicates that dye entry is rapid and via the apical surface. Cooling to $4^{\circ} \mathrm{C}$ and high extracellular calcium both reduce dye loading. Pretreatment with EGTA, a condition that breaks tip links and prevents mechanotransducer channel gating, abolishes subsequent dye loading in the presence of calcium. Dye loading recovers after calcium chelation with a time course similar to that described for tip-link regeneration. Myo7a mutant hair cells, which can transduce but have all mechanotransducer channels normally closed at rest, do not label with FM1-43 unless the bundles are stimulated by large excitatory stimuli. Extracellular perfusion of FM1-43 reversibly blocks mechanotransduction with half-blocking concentrations in the low mi-
\end{abstract}

cromolar range. The block is reduced by high extracellular calcium and is voltage dependent, decreasing at extreme positive and negative potentials, indicating that FM1-43 behaves as a permeant blocker of the mechanotransducer channel. The time course for the relief of block after voltage steps to extreme potentials further suggests that FM1-43 competes with other cations for binding sites within the pore of the channel. FM1-43 does not block the transducer channel from the intracellular side at concentrations that would cause complete block when applied extracellularly. Calcium chelation and FM1-43 both reduce the ototoxic effects of the aminoglycoside antibiotic neomycin sulfate, suggesting that FM1-43 and aminoglycosides enter hair cells via the same pathway.

Key words: hair cell; cochlea; mechanotransduction; ion channel; endocytosis; aminoglycosides; myosin VIIA; FM1-43
Sensory hair cells are polarized neuroepithelial cells of the inner ear. They have an apical surface specialized for the reception and transduction of stimuli and a basolateral surface specialized for a number of different functions, including the release of neurotransmitter. Electron microscopic studies (Forge and Richardson, 1993; Hasson et al., 1997; Kachar et al., 1997; Richardson et al., 1997; Seiler and Nicolson, 1999) have provided evidence for a large pool of vesicles, many of which are part of an endocytotic pathway, lying just below the apical surface of the hair cell. The function of this pathway is unknown, although membrane turnover is likely to play an important role in the assembly and maintenance of the mechanotransduction apparatus of the hair cell.

The amphipathic styryl dye FM1-43 has become a key tool for investigating endocytosis and exocytosis (Betz and Bewick 1992; Betz et al., 1992, 1996; Cochilla et al., 1999). The dye has a divalent cationic head group and a lipophilic tail, and it reversibly partitions into the outer leaflet of the cell membrane. FM1-43 fluoresces weakly in an aqueous environment, and its quantum yield increases by two orders of magnitude on intercalation in the

\footnotetext{
Received Feb. 6, 2001; revised June 7, 2001; accepted June 29, 2001.

This work was supported by grants from The Wellcome Trust (Grant 057410/Z/ 99/Z), Defeating Deafness, and The Medical Research Council. J.E.G. is a Royal Society University Research Fellow. We thank Fabien Faucheux for his help with the scanning electron microscopy and Angie Rau for providing the template for Figure $2 B$.

J.E.G. and W.M. contributed equally to this work.

Correspondence should be addressed to Dr. Guy P. Richardson and Dr. Corné J. Kros, School of Biological Sciences, The University of Sussex, Falmer, Brighton, BN19QG, UK. E-mail: g.p.richardson@sussex.ac.uk and c.j.kros@sussex.ac.uk.

J. E. Gale's current address: Department of Physiology, University College London, Gower Street, London, WC1E 6BT, UK.

Copyright (ㄷ) 2001 Society for Neuroscience $\quad 0270-6474 / 01 / 217013-13 \$ 15.00 / 0$
}

lipid membrane (Betz et al., 1996). In most cells, FM1-43 is unable to penetrate the lipid bilayer (Betz et al., 1996; Cochilla et al., 1999) and is internalized as a result of endocytosis. Recent evidence from Xenopus (Nishikawa and Sasaki, 1996), zebrafish larvae (Seiler and Nicolson, 1999), and the bullfrog sacculus (Gale et al., 2000) has shown that sensory hair cells can be selectively labeled by FM1-43. In Xenopus, mechanotransducer channel blockers and a high concentration of divalent cations were reported to inhibit dye labeling, and electron microscopy indicated that the mitochondria and endoplasmic reticulum of the hair cells were primarily labeled. These observations led to the suggestion that the dye enters via the mechanotransduction channel (Nishikawa and Sasaki, 1996). In zebrafish, FM1-43 labeling of hair cells was found to be both calcium and calmodulin dependent, leading to the conclusion that dye entry was via a rapid apical endocytotic pathway (Seiler and Nicolson, 1999).

Eight zebrafish circler mutants have been described with defects in sensory hair-cell function, including mechanotransduction (Nicolson et al., 1998). In five of these mutants, the internalization of FM1-43 by hair cells is defective, suggesting that dye uptake is closely linked to transduction (Seiler and Nicolson, 1999). The hair cells in these mutants also show reduced sensitivity to the ototoxic aminoglycoside antibiotics. One of these mutants, mariner, has mutations in the myosin VIIA gene (Ernest et al., 2000). Myosin VIIA is required for aminoglycoside accumulation in mouse cochlear hair cells (Richardson et al., 1997). Little is known about FM1-43 dye loading in mammalian auditory hair cells or whether it is defective in mouse Myo7a mutants. We therefore characterized the mechanism of FM1-43 dye entry in mouse cochlear hair cells. The results indicate that FM1-43 behaves as a permeant blocker of the mechanotransducer channel. 
Dye entry in Myo7a mutant hair cells fails because the transducer channels are all closed at rest.

\section{MATERIALS AND METHODS}

Culture preparation. Cochlear cultures from CD1, Myo $7 a^{6 J}$, and Myo $7 a^{4626 S B}$ mice were prepared as described previously (Richardson and Russell, 1991). In brief, cochleas were dissected from 1-2 d postnatal (P) pups in HEPES-buffered (10 mM, pH 7.2) HBSS (HBHBSS), placed onto collagencoated glass coverslips, fed one drop of complete medium $(10 \%$ horse serum, 90\% Eagle's MEM in Earle's salt solution with an additional $10 \mathrm{~mm}$ HEPES, pH 7.2), sealed into Maximow slide assemblies, and maintained at $37^{\circ} \mathrm{C}$ for $1-3 \mathrm{~d}$. Mutant mouse pups were obtained from crosses between heterozygous female and homozygous male mice carrying either the $M y o 7 a^{6 J}$ or the Myo7a $a^{4626 S B}$ mutations. All offspring therefore were either heterozygous or homozygous, and cultures prepared from the homozygous mutants were readily distinguished from those prepared from heterozygous animals on the basis of hair bundle morphology, as observed by differential interference contrast (DIC) microscopy.

Dye labeling procedures. Stock solutions of $3 \mathrm{~mm}$ FM1-43 [N-(3triethylammoniumpropyl)-4-(4-(dibutylamino)styryl) pyridiniumdibromide; Molecular Probes, Eugene, OR; MW 611 as the dibromide salt, 451 for the cation] were dissolved in either DMSO or water. For testing high intracellular concentrations of FM1-43, a $10 \mathrm{mM}$ stock solution was prepared in water. Some experiments were conducted with the larger FM1-43 analog, FM3-25 [ $N$-(3-triethylammoniumpropyl)-4-(4-(dioctadecylamino)styryl) pyridinium di-4-chlorobenzenesulfonate; Molecular Probes; MW 1226 as the dichlorobenzenesulfonate salt, 843 for the cation]. For this molecule, stock solutions of $3 \mathrm{~mm}$ were dissolved in DMSO. Two methods were used to study FM1-43 dye labeling: bath application or local perfusion. For bath application, the coverslips with adherent cultures were removed from the Maximow slide assemblies and transferred through a series of Columbia staining jars, each containing 8 $\mathrm{ml}$ of solution. Unless stated otherwise, all experiments were performed at room temperature $\left(20-23^{\circ} \mathrm{C}\right)$. The coverslips were first immersed in HBHBSS for $15 \mathrm{~min}$, transferred to HBHBSS containing $3 \mu \mathrm{M}$ FM1-43 for $10 \mathrm{sec}$, and immediately washed three times (10 sec each wash) in HBHBSS. The coverslips were then placed in a glass-bottomed Perspex chamber containing $1.5 \mathrm{ml}$ HBHBSS and viewed with an upright microscope equipped with epifluorescence optics and FITC filters (excitation $488 \mathrm{~nm}$, emission $520 \mathrm{~nm}$ ) using $10 \times$ dry and $40 \times$ water immersion lenses. Images were captured from live cultures at fixed time points after dye application, either on $35 \mathrm{~mm}$ film (Kodak Tri-X film rated at 1600 ASA) or using a 12-bit cooled charge-coupled device (CCD) camera (SPOT-JNR, Diagnostics Inc.). When testing the effects of elevated extracellular calcium and EGTA, these were included in the initial 15 min preincubation bath, in the FM1-43 dye solution itself, and in the first two washes after incubation with the dye, unless indicated otherwise. Experiments at $4^{\circ} \mathrm{C}$ were performed in a cold room to ensure accurate temperature control. All experiments reported were performed on a minimum of three separate cultures, each of which usually contained two apical and two basal-coil explants. The total numbers of apical and basal-coil explants examined for each experimental condition are provided in Results, in the reference to the appropriate Figure part.

For local perfusion of FM1-43, the coverslips were placed directly in the glass-bottomed Perspex chamber after removal from the Maximow slides, covered with HBHBSS, and transferred to the microscope stage. The bath chamber was then continuously perfused with HBHBSS, and 3 or $6 \mu \mathrm{M}$ FM1-43 was applied to the apical surfaces of hair cells using micropipettes with a 2-4 $\mu \mathrm{m}$ internal tip diameter that were connected to a picospritzer.

EGTA recovery experiments. Calcium-free HBHBSS with EGTA was prepared from $10 \times$ calcium/magnesium-free HBSS by the addition of (in mM): $0.5 \mathrm{MgCl}_{2}, 0.4 \mathrm{MgSO}_{4}, 5$ EGTA or 5 BAPTA, and $10 \mathrm{HEPES}, \mathrm{pH}$ 7.2. Cultures were incubated in either HBHBSS or HBHBSS containing $5 \mathrm{~mm}$ EGTA for $15 \mathrm{~min}$, washed twice in HBHBSS (1 min each wash), returned to the Maximow slide assemblies, fed one drop of complete medium $(\sim 50 \mu \mathrm{l})$, and placed at $37^{\circ} \mathrm{C}$ for $1,4,8$, or $24 \mathrm{hr}$. At the selected time points the cultures were labeled with FM1-43 dye using the bath application method described above.

Confocal microscopy. Confocal images were captured using a Bio-Rad MRC600 laser scanning confocal microscope. Images were captured as rapidly as possible using custom-written macro subroutines. Two different sets of images were obtained. First, stacks of images were obtained at two or three different focal planes ( $Z$ stacks) over a $60 \mathrm{sec}$ period. The sampling intervals between stacks were 2.9 (for two levels) and $5 \mathrm{sec}$ (for three levels). Second, images were obtained at a single focal plane 7-10 $\mu \mathrm{m}$ below the apical surface of the hair cell, with an interval of $0.875 \mathrm{sec}$ between frames (i.e., a sampling rate of $1.15 \mathrm{~Hz}$ ). All confocal experiments were performed at $25-28^{\circ} \mathrm{C}$.

Quantitation of FM1-43 loading. The fluorescence intensity histograms of images obtained using the cooled CCD camera were checked to confirm that the dynamic range of the camera was not saturated. A $70 \times$ 700 pixel region $(\sim 11 \times 110 \mu \mathrm{m})$ was selected that covered the row of hair cells of interest, and the average fluorescence intensity was measured using Adobe Photoshop or the image analysis package Lucida (Kinetic Imaging). Nonspecific background fluorescence in the unlabeled area lateral to the outer hair cells was measured and subtracted from the signal to give a value for the intensity of fluorescence in arbitrary units equivalent to the amount of FM1-43 loading. The camera acquisition parameters were fixed for all experiments, allowing comparison between time-matched experiments. In addition, time-matched controls were performed for all experiments in which pharmacological treatments were applied.

Confocal images were quantified in the same way except that fluorescence intensity was measured from hair bundles or cytoplasmic regions of single hair cells. The change in fluorescence from the resting level was calculated by subtracting the average fluorescence intensity from the hair-cell region before local perfusion of FM1-43. Any changes in the background fluorescence over the period of the experiment were monitored to confirm the viability of experiments. The data were fitted with a sigmoidal function using the nonlinear curve fitting function in Origin (OriginLab).

Recordings of mechano-electrical transduction currents. Cochleas were acutely isolated from CD1 mice, aged P5-P7, and immobilized under a nylon mesh. Mechano-electrical transducer currents were elicited in apical-coil outer hair cells using fluid-jet stimulation ( $45 \mathrm{~Hz}$ sine waves or steps filtered at $1 \mathrm{kHz}$ unless specified otherwise) and recorded under whole-cell voltage clamp (HEKA EPC7 or EPC8) as described previously (Kros et al., 1992). Mechanical steps filtered at $1 \mathrm{kHz}$ were sigmoidal but could be approximately fitted with a time constant of 140 $\mu$ sec. Membrane capacitance $\left(C_{\mathrm{m}}\right)$ was $6.11 \pm 0.05 \mathrm{pF}$, and series resistance after electronic compensation of up to $50 \%\left(R_{\mathrm{s}}\right)$ was $5.20 \pm$ $0.17 \mathrm{M} \Omega$, resulting in voltage-clamp time constants of $31.8 \pm 1.1 \mu \mathrm{sec}$ $(n=59)$. Extracellular solutions were bath applied at a rate of $6 \mathrm{ml} / \mathrm{hr}$ and contained (in $\mathrm{mM}$ ): $135 \mathrm{NaCl}, 5.8 \mathrm{KCl}, 1.3 \mathrm{CaCl}_{2}, 0.9 \mathrm{MgCl}_{2}, 0.7$ $\mathrm{NaH}_{2} \mathrm{PO}_{4}, 2$ Na-pyruvate, 5.6 D-glucose, and 10 HEPES. Amino acids and vitamins for Eagle's MEM were added from concentrates (Life Technologies). The $\mathrm{pH}$ was adjusted to 7.5 with $1 \mathrm{M} \mathrm{NaOH}$. Intracellular solutions contained (in $\mathrm{mM}$ ): $147 \mathrm{CsCl}, 2.5 \mathrm{MgCl}_{2}, 1$ EGTA, 2.5 $\mathrm{Na}_{2} \mathrm{ATP}, 5$ HEPES; $\mathrm{pH}$ adjusted to 7.3 with $1 \mathrm{~m} \mathrm{CsOH}$. Hair cells were locally superfused with FM1-43 added to the extracellular solution at concentrations ranging from 0.3 to $20 \mu \mathrm{M}$, or with FM3-25 at 6 or $30 \mu \mathrm{M}$ through a pipette with a tip diameter of $\sim 200 \mu \mathrm{m}$. In some experiments, calcium in the superfusion solution was reduced to $100 \mu \mathrm{M}$ or increased to 5 or $10 \mathrm{~mm}$, and magnesium was omitted. For every solution change, the fluid jet used for stimulating the hair bundles was filled with the new solution by suction through its tip to prevent dilution of the superfusate around the hair bundle during stimulation. Intracellular effects of FM1-43 were tested by its inclusion in the patch pipette (up to $200 \mu \mathrm{M}$ ). All membrane potentials were corrected for a $-4 \mathrm{mV}$ liquid junction potential between pipette and bath solutions but not for any voltage drop (in most cases $<5 \mathrm{mV}$ at extreme potentials) across the residual series resistance. All experiments were conducted at room temperature $\left(22-25^{\circ} \mathrm{C}\right)$

All means given in text and Figures are expressed \pm SEM. Statistical analyses were performed using $t$ tests or one- or two-way ANOVA as appropriate. The criterion for statistical significance was set at $p<0.05$.

Fluid-jet stimulation of Myo7a mutant hair cells in the presence of FM1-43. Cochlear cultures from homozygous Myo7a ${ }^{4626 S B}$ mice were locally superfused with $3 \mu \mathrm{M}$ FM1-43, and then individual hair cells were stimulated using the fluid-jet described above. In these experiments, large, alternating excitatory and inhibitory step stimuli of $2 \mathrm{sec}$ duration were applied over $60 \mathrm{sec}$ such that the total excitatory stimulus duration amounted to $16 \mathrm{sec}$. Fluorescence images were captured before and after stimulation using the cooled CCD camera with a fixed exposure time of $2 \mathrm{sec}$.

Scanning electron microscopy. The following experimental procedures were performed at room temperature using cultures from 1- to 2-d-old mice that had been maintained in vitro for $1 \mathrm{~d}$. To test the effects of calcium chelation on the response of hair cells to the ototoxic aminogly- 

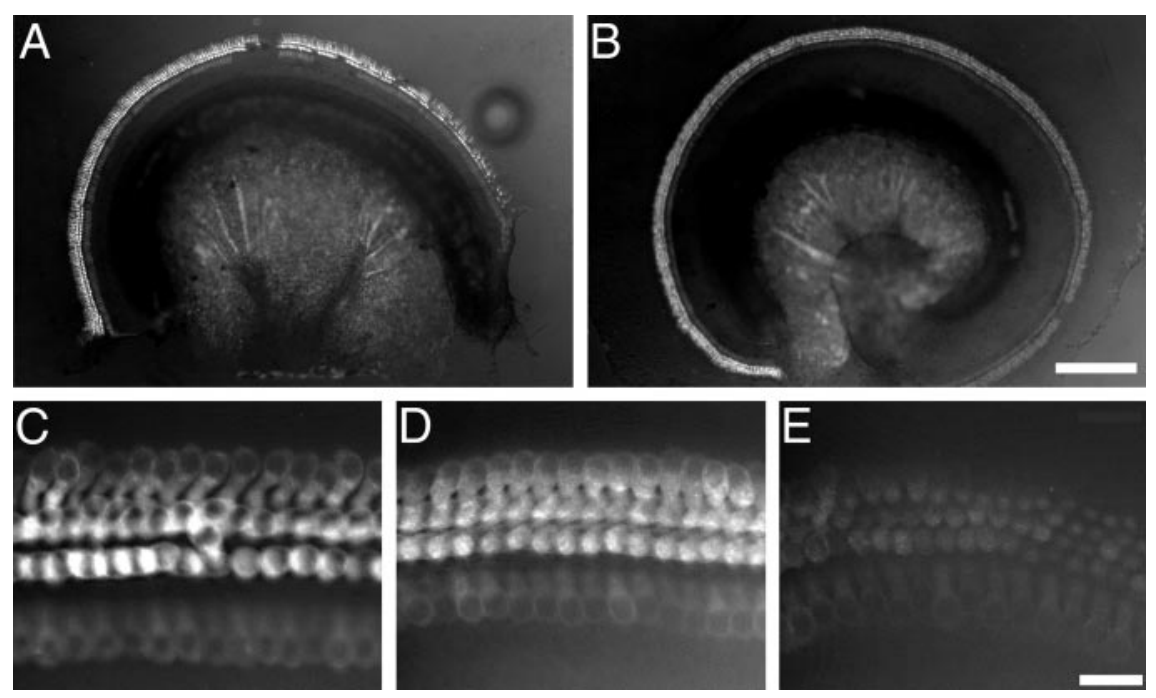

Figure 1. Selective labeling of hair cells in cochlear cultures with FM1-43. $A$, Low-magnification fluorescent image of a 2-d-old basal-coil cochlear culture taken $30 \mathrm{~min}$ after a $10 \mathrm{sec}$ exposure to $3 \mu \mathrm{M}$ FM1-43. $B$, Image of a 2-d-old apical-coil cochlear culture taken 35 min after a $10 \mathrm{sec}$ exposure to $3 \mu \mathrm{M}$ FM1-43. FM1-43 labels hair cells, whereas the surrounding supporting cells do not load with the dye. A gradient in the amount of dye loading can be seen running from the hair cells at the basal, more mature end of the apical coil (left in $B$ ) to those at the apical end (right in $B$ ). In both $A$ and $B$, some cells within the neural tissue in the center of the culture appear to have loaded with the dye. $C, D$, At higher magnification, differences in the dye loading of inner and outer hair cells can be seen in both the basal-coil culture $(C)$ and the basal end of the apical-coil culture $(D)$. Outer hair cells load more dye than inner hair cells after a $10 \mathrm{sec}$ bath application of the dye. $E$, Hair cells at the apical end of the apical coil load less dye than those at the basal end. At the apical end, the inner and outer hair cells load equivalent amounts of the dye. In $C-E$, the single row of inner hair cells lies below the three rows of outer hair cells. Scale bars: $A, B, 250 \mu \mathrm{m} ; C-E, 25 \mu \mathrm{m}$. coside antibiotic neomycin sulfate, cultures were washed twice $(5 \mathrm{~min}$ each wash) with either $2 \mathrm{ml}$ of HBHBSS or $2 \mathrm{ml}$ of calcium-free HBSS containing $5 \mathrm{~mm}$ BAPTA and returned to HBHBSS containing normal levels of extracellular calcium $(1.3 \mathrm{mM})$. Half of the cultures from each group (HBHBSS or BAPTA-treated) were then incubated in HBHBSS for $1 \mathrm{hr}$, and the other half were incubated in HBHBSS containing $1 \mathrm{~mm}$ neomycin sulfate, also for $1 \mathrm{hr}$. To test the effects of FM1-43 dye on hair cells and the response of hair cells to neomycin exposure in the presence of FM1-43, cultures were incubated in either HBHBSS or HBHBSS containing 3 or $30 \mu \mathrm{M}$ FM1-43 for $10 \mathrm{~min}$. Neomycin sulfate was then added to a concentration of $1 \mathrm{~mm}$ to half of the cultures from each of the three groups (HBHBSS or FM1-43-treated, 3 and $30 \mu \mathrm{M}$ ), and the cultures were further incubated for $1 \mathrm{hr}$. After the end of the treatment period, cultures were washed once in HBHBSS, fixed in $2.5 \%$ glutaraldehyde in $0.1 \mathrm{~m}$ sodium cacodylate, $\mathrm{pH} 7.4$, containing $4 \mathrm{~mm} \mathrm{CaCl} 2$ for $1 \mathrm{hr}$, washed three times in $0.1 \mathrm{M}$ sodium cacodylate buffer, and post-fixed in $1 \%$ osmium tetroxide. After osmication, cultures were dehydrated through a series of ascending concentrations of ethanol, critical point dried from liquid $\mathrm{CO}_{2}$, mounted on stubs, sputter coated with gold, and viewed in a Leica Leo S420 scanning electron microscope. For the BAPTA pretreatment experiments, a minimum of three basal-coil explants and four apical-coil explants were examined in each of the four conditions. For the experiments with FM1-43, a minimum of four basal and four apical-coil explants were examined in each of the six conditions.

\section{RESULTS}

\section{Characteristics of FM1-43 loading in cochlear cultures}

A $10 \mathrm{sec}$ bath application of FM1-43 results in the selective labeling of inner and outer hair cells in organotypic cultures of the mouse cochlea (Fig. $1 A, B$ ). Little or no dye labeling is observed in the supporting cells immediately surrounding the hair cells, in the cellular outgrowth zone lying peripheral to the bands of hair cells, or in the cells of the greater epithelial ridge that are located adjacent to the inner hair cells. FM1-43 dye labeling is also observed, but to a much lesser extent, in cells located within the central modiolar core of the culture where the spiral ganglion neurons innervating the hair cells are located. The dye-loading properties of the cells in this latter location were not investigated further. Hair cells in basal-coil cochlear cultures (Fig. $1 A, C$ ) load more dye than those in apical-coil cultures (Fig. $1 B, D, E)$. Within apical coils a gradient of FM1-43 labeling is observed (Fig. 1B), with hair cells at the basal end of the coil (Fig. $1 D)$ labeling most intensely and those at the extreme apex of the apical coil labeling the least (Fig. 1E). This gradient of labeling shifts with the age of the cultures so that hair cells located more apically begin to label more intensely in older cultures. After $3 \mathrm{~d}$ in vitro, expression is more homogenous along the length of apical-coil cultures (data not shown), presumably reflecting maturation of the hair cells. However, in cultures up to the equivalent of postnatal day 4 (the oldest tested), hair cells in basal-coil cultures are always more strongly labeled than those from the apical coil. Dye loading by hair cells was quantified in five apicaland five basal-coil cultures. The average measured fluorescence intensity in hair cells in basal-coil cultures is twice that measured in hair cells at the basal end of the apical coil. Labeling of the outer hair cells is three times greater than that of inner hair cells in both basal and apical coils. The pattern of labeling appears qualitatively similar in the two cell types.

\section{Time course and site of FM1-43 loading}

Confocal microscopy combined with local perfusion of the apical surface of hair cells revealed the site of entry and the time course of FM1-43 loading. Consecutive optical sections were imaged at three focal levels (Z-planes) in time (T) to form a depth and time (ZT) series (Fig. $2 A, B$ ). Focal planes were $7.5 \mu \mathrm{m}$ apart, with the first located at the level of the hair bundles on the surface of the hair cells, the second at the level of the cuticular plate just below the cell surface, and the third just sectioning the nucleus. Sequential images from the three levels show dye loading during and after a $5 \mathrm{sec}$ puff application of $6 \mu \mathrm{M}$ FM1-43 (Fig. $2 A$ ). Initially, during the dye pulse, strong labeling of the hair bundles is observed as FM1-43 partitions into the membranes of the stereocilia that comprise these structures (Fig. 2A,C). Once local perfusion of the dye stops, the fluorescent signal declines as dye partitions out of the membrane. FM1-43 dye is observed within the cell cytoplasm almost immediately after the pulse onset at the level of the cuticular plate (Fig. $2 A, C$ ). After a short delay, FM1-43 fluorescence is observed at the nuclear level (Fig. 2A,C) but not within the nucleus itself (Fig. $2 A$ ).

Initially the dye appears to be distributed relatively diff usely within the cell. However, $30 \mathrm{~min}$ after a $10 \mathrm{sec}$ bath application the dye appears to concentrate in punctate structures that stain intensely with dye (Fig. 2D). Similar structures are observed after puff application of FM1-43 (data not shown). The same loading characteristics were seen in both basal and apical-coil cultures and in all cultures in which ZT series were taken $(n=17$ in total). In 
Figure 2. Time course of dye loading revealed by confocal microscopy. $A$, A series of images taken at the time points indicated at the three focal levels, $L 1, L 2$, and $L 3$ indicated in $B$. The vertical arrow indicates the onset of dye application $(6 \mu \mathrm{M}$ lasting for $5 \mathrm{sec}$ ). The frame is an area measuring $80 \times 55$ $\mu \mathrm{m}$. The top row, $L 1$, shows consecutive images of the "v"-shaped bundles of stereocilia at the surface of the hair cells in which a transient peak of dye labeling is observed. The middle row, L2, shows consecutive images taken at a focal plane close to the cuticular plate at the apical pole of the cell. Dye loads into this region rapidly and is then retained. The bottom row, L3, shows images taken at the level of the cell nucleus. Note the absence of fluorescence in the nucleus, presumably caused by the lack of membrane-bound organelles. It can be seen that dye enters the apex of the cell before being visualized at the level of the nucleus. The approximate time is indicated in seconds. $B$, Schematic diagram showing the three focal planes at which the ZT series were captured and the approximate position of the puffer pipette used to apply $6 \mu \mathrm{M}$ FM1-43 for $5 \mathrm{sec}$. $C$, The change in fluorescence at the three focal levels as a function of time (adjusted for the interval between frame capture at each level) in a basal-coil outer hair cell. The graph shows that dye partitions into the outer leaflet of the stereocilia and then departitions $(L 1)$. Dye is then observed at the level of the cuticular plate (L2) and is subsequently seen at the level of the cell nucleus, close to the base of the cell (L3). D, Confocal image taken $30 \mathrm{~min}$ after exposure to the dye. At this time point
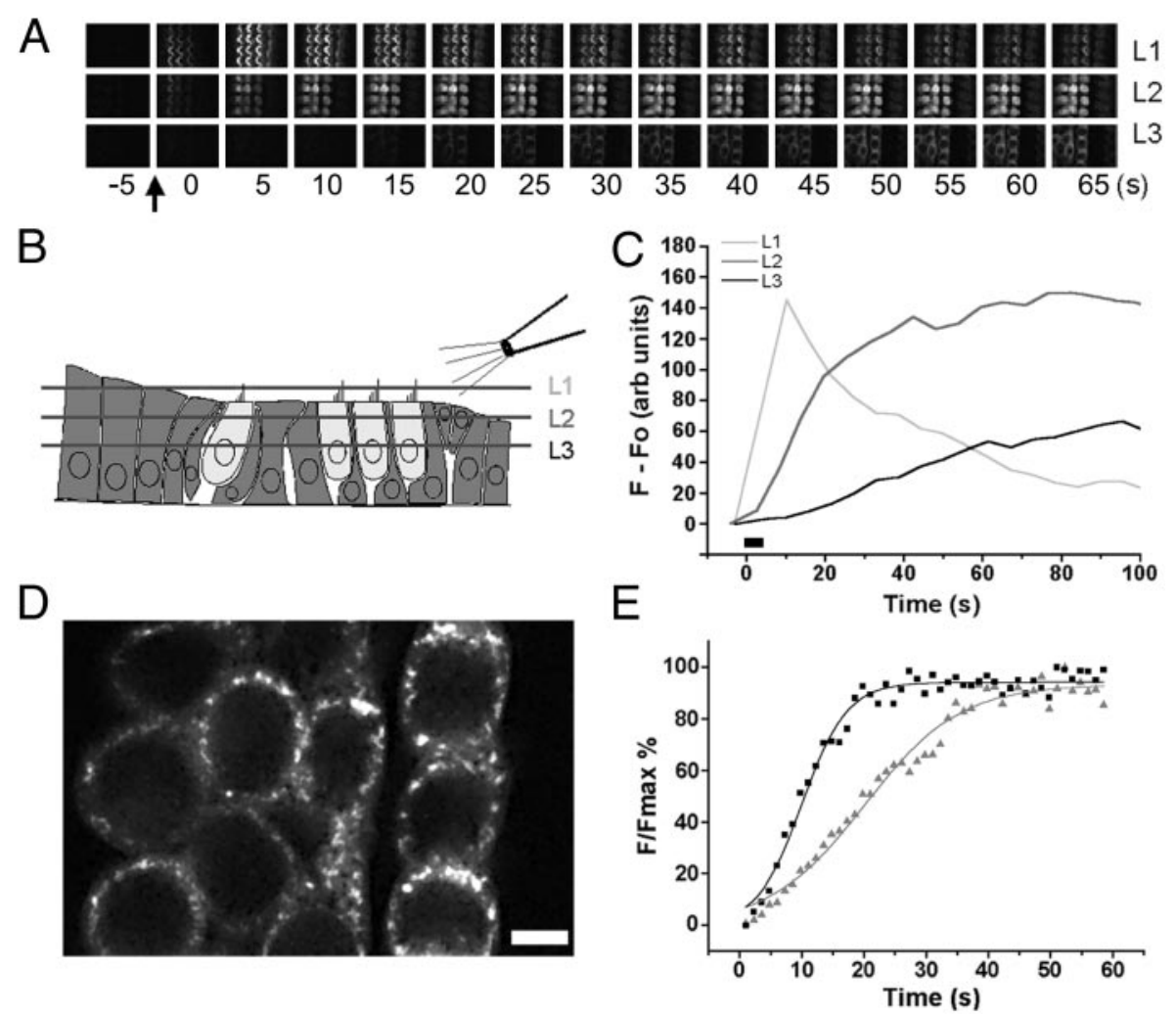

the dye is observed in punctate structures within the cytoplasm of the cell. Scale bar, $5 \mu \mathrm{m}$. E, Comparison of dye loading in apical ( $\mathbf{\Delta})$ and basal-coil ( $\square$ ) outer hair cells. Images were captured at a single focal plane, $7.5 \mu \mathrm{m}$ below the apex. The interval between frames is 0.85 sec. The changes in fluorescence were normalized and have been fitted with a sigmoidal (Boltzmann) function with $t_{1 / 2}$ max values of $10.0 \mathrm{sec}$ for basal-coil and $20.1 \mathrm{sec}$ for apical-coil outer hair cells.

additional cultures that were examined, some of the outer hair cells were positioned such that the confocal optical section sliced the cells obliquely giving a cross section through the apical-basal axis of the cell. The images obtained from such cells provide further confirmation that the dye enters at the cell apex and then spreads to the basal pole (for movie, see http://www.geribolsover.physiol.ucl.ac.uk/pic/ Gale_with_still.html).

Series of timed confocal images taken at a single focal level, 7.5 $\mu \mathrm{m}$ below the apical surface of the hair cells, were used to analyze the kinetics of FM1-43 loading in apical and basal-coil cultures. FM1-43 entry into outer hair cells follows a sigmoidal time course in both the basal and apical coils. However, there is a significant difference in the kinetics of loading in basal and apical-coil outer hair cells (Fig. 2E). Data from a total of 44 outer hair cells in 13 different culture preparations were fitted with a sigmoidal function from which time to half-maximum values $\left(t_{1 / 2} \max \right)$ were obtained. The $t_{1 / 2 \max }$ for FM1-43 loading in basal-coil outer hair cells is $14.0 \pm 1.2 \mathrm{sec}(n=23)$, significantly different $(p<0.0001)$ from apical-coil outer hair cells in which the mean $t_{1 / 2}$ max is $21.2 \pm 0.9 \sec (n=21)$. The significant difference observed in the rate of dye accumulation in basal-coil and apical-coil hair cells may explain the different amounts of labeling observed in apicaland basal-coil hair cells under bath application conditions. The time course of dye loading in inner hair cells was compared with that in outer hair cells. The $t_{1 / 2 \text { max }}$ for dye loading in inner hair cells in basal-coil cultures is $24.6 \pm 2.0(n=6)$, twice that observed in adjacent outer hair cells. The $t_{1 / 2}$ max for dye loading in inner hair cells in the basal-end of apical coils is $33.6 \pm 2.8 \mathrm{sec}$ $(n=6), 58 \%$ greater than the value for outer hair cells from the same location.

To test whether larger fluorescent compounds would behave in a manner similar to that of FM1-43, cochlear cultures were puff perfused with a $5 \mathrm{sec}$ pulse of $1 \mu \mathrm{M}$ FITC-conjugated poly-lysine (average molecular weight $20 \mathrm{kDa}$ ). Intracellular labeling of hair cells with FITC-conjugated poly-L-lysine was not observed under these conditions.

\section{FM1-43 loading is blocked at low temperature and by elevated external calcium}

We investigated the effects of low temperature and elevated extracellular calcium on FM1-43 dye loading. Cochlear cultures were incubated at $4^{\circ} \mathrm{C}$ for $15 \mathrm{~min}$ before a $10 \mathrm{sec}$ bath application of FM1-43 at $4^{\circ} \mathrm{C}$ and were then washed three times in cold HBHBSS. The cultures were observed and images recorded at room temperature. Relative to controls labeled at room temperature ( $n=3$ basal coils, 4 apical coils) (Fig. $3 A$ ), there is little or no labeling of FM1-43 observed in inner or outer hair cells exposed to dye at $4^{\circ} \mathrm{C}$ ( $n=4$ basal coils, 3 apical coils) (Fig. $\left.3 B\right)$. A similar protocol was used at room temperature to test the effects of elevated external calcium. In comparison to control cultures labeled with FM1-43 in normal $(1.3 \mathrm{~mm})$ extracellular calcium ( $n=7$ basal coils, 7 apical coils) (Fig. $3 C$ ), dye labeling of hair cells was completely blocked when FM1-43 was applied in the presence of $10 \mathrm{~mm}$ calcium after a $15 \mathrm{~min}$ preincubation in HBHBSS containing $10 \mathrm{~mm}$ calcium $(n=5$ basal coils, 5 apical coils) (Fig. 3D).

\section{Pretreatment with calcium chelator blocks dye labeling}

To determine whether dye labeling is directly dependent on external calcium, cultures were exposed to FM1-43 dye in the presence of $5 \mathrm{~mm}$ EGTA. In these experiments the cultures were not preincubated in HBHBSS containing EGTA. EGTA was only 

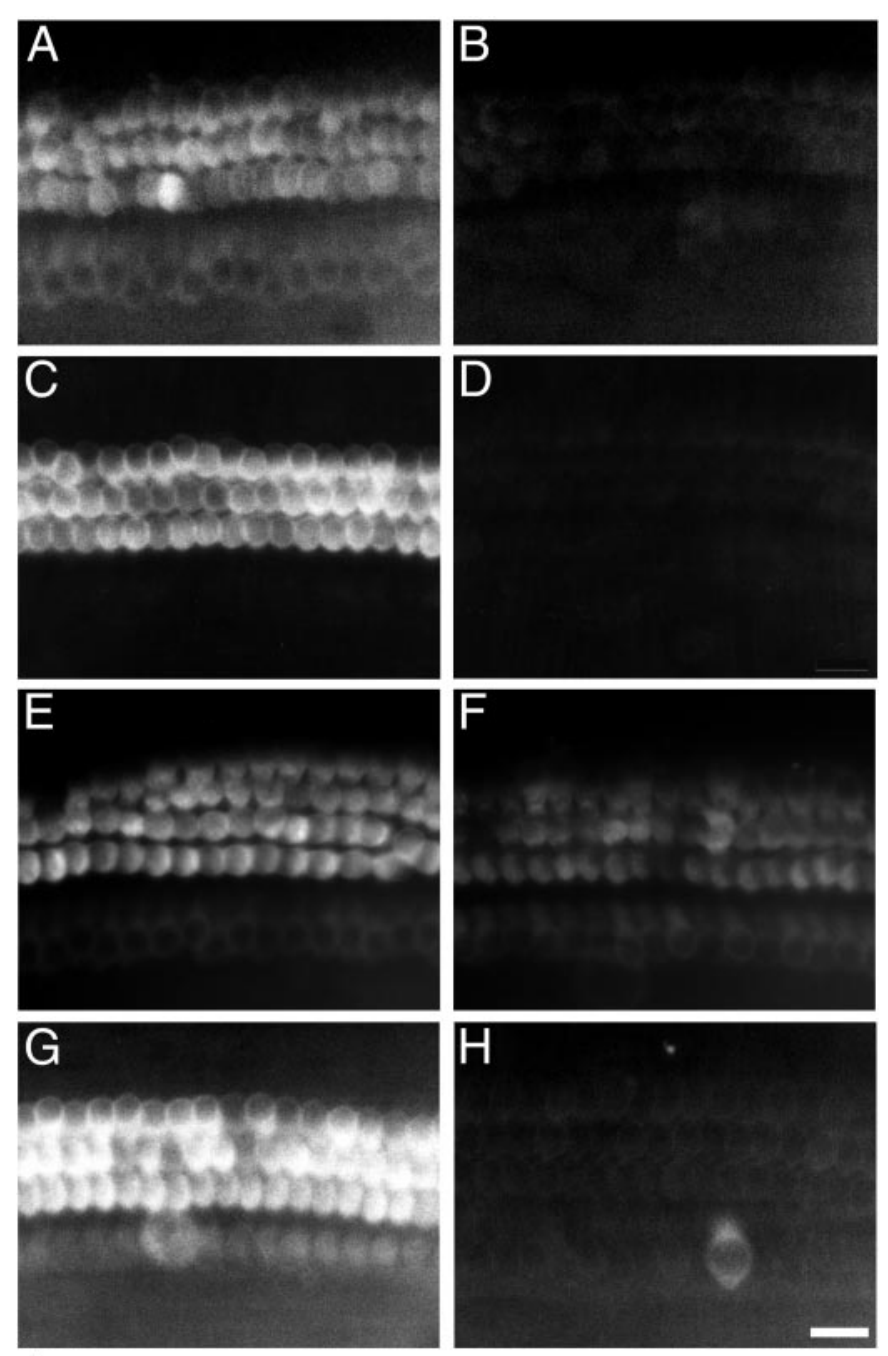

I

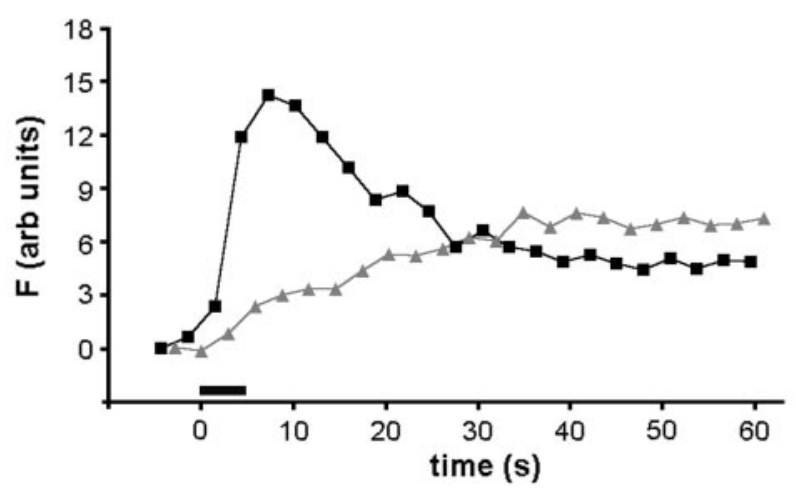

Figure 3. Effects of cooling, elevated extracellular calcium, and calcium chelation on FM1-43 loading. All images were captured from basal-coil hair cells 6-8 min after bath application of $3 \mu \mathrm{M}$ FM1-43 for $10 \mathrm{sec}$. The images shown in $A, C, E$, and $G$ are from the corresponding age and time-matched controls for the images shown in $B, D, F$, and $H$, respectively. $A, B$, Dye loading at room temperature $(A)$ and at $4^{\circ} \mathrm{C}(B)$. Labeling is blocked when the dye is applied at low temperature. $C, D$, Cultures preincubated and exposed to dye in the presence of HBHBSS $(C)$ and preincubated and exposed to dye in the presence of HBHBSS containing $10 \mathrm{~mm}$ calcium $(D)$. Labeling is blocked when the dye is applied in HBHBSS with $10 \mathrm{~mm}$ calcium. $E, F$, Dye loading in normal HBHBSS $(E)$ and HBHBSS containing $5 \mathrm{~mm}$ EGTA $(F)$. Labeling is slightly reduced when dye is applied in HBHBSS containing EGTA. $G, H$, Dye loading in cultures preincubated for $15 \mathrm{~min}$ in HBHBSS $(G)$ or HBHBSS containing 5 mM EGTA $(H)$ before FM1-43 dye application in the presence of normal extracellular calcium. Labeling is substantially present in the dye solution. Relative to control cultures $(n=9$ basal coils, 8 apical coils) (Fig. $3 E$ ), the presence of EGTA during the $10 \mathrm{sec}$ bath application step reduces but does not prevent dye loading ( $n=6$ basal coils, 4 apical coils) (Fig. $3 F$ ).

Although dye application in the presence of EGTA reduces dye labeling but does not abolish it, dye loading in the presence of normal extracellular calcium $(1.3 \mathrm{mM})$ can be blocked, relative to control cultures preincubated in HBHBSS alone ( $n=10$ basal coils, 9 apical coils) (Fig. $3 G$ ), by pre-exposing cultures to $5 \mathrm{~mm}$ EGTA for $15 \min (n=11$ basal coils, 10 apical coils) (Fig. $3 H$ ). This effect of pre-exposure to calcium chelators does not reach completion immediately. In two separate cultures, we used local perfusion of dye to measure the effect of calcium chelation during a 45 min period after the 15 min EGTA treatment. When a $5 \mathrm{sec}$ local pulse of the dye is applied at 15 min intervals during a 45 min post-EGTA exposure period in the presence of normal extracellular calcium, a progressive decline is observed in the amount of loading (data not shown). Block is complete by $45 \mathrm{~min}$. Although dye loading is blocked by pretreatment with calcium chelators, it does not abolish the labeling of stereocilia observed during and shortly after puff perfusion of the dye. This transient labeling presumably largely results from the dye partitioning into and out of the outer leaflet of the stereocilia plasma membrane. This observation was exploited to determine whether dye labeling in cultures not exposed to EGTA is observed inside stereocilia before visualization at the apical pole of the cell. Thus we measured dye labeling of the stereocilia in EGTA-treated hair cells and subtracted this signal from the signal measured in the stereocilia of sham-treated controls. The subtracted signal, an indicator of dye loading within the hair bundle, was compared with the dye loading observed $10 \mu \mathrm{m}$ below the stereocilia, just below the level of the cuticular plate. As shown in Figure 3I, the subtracted signal shows an initial increase followed by a decline to a plateau above baseline. The initial increase in the subtracted signal precedes the increase in signal observed in the cell body, indicating that the dye first enters the stereocilia and then subsequently labels the apical pole of the cell.

\section{Recovery of FM1-43 dye entry after block by calcium chelation}

To examine whether the block by calcium chelation is reversible, EGTA-treated and HBHBSS-treated control cultures were returned immediately to complete medium and incubated at $37^{\circ} \mathrm{C}$ for 1, 4, 8, and $24 \mathrm{hr}$ before FM1-43 labeling using the bath application method. After $1 \mathrm{hr}$ in culture after EGTA treatment, the block is close to $100 \%$ effective ( $n=4$ basal coils, 4 apical coils) (Fig. 4A,B). However, the blockade of FM1-43 loading is

reduced by the 15 min pretreatment with EGTA. Occasional, solitary, dye-labeled hair cells observed in EGTA-treated cultures $(\sim 2-5$ per culture) are considered to be damaged cells. Scale bars (shown in $H$ for $A-H): 25 \mu \mathrm{m}$. $I$, The change in fluorescence measured in sham-treated control cultures at two confocal planes, one at the level of the stereocilia

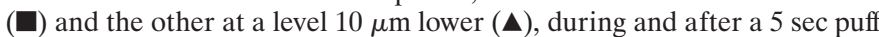
application of $6 \mu \mathrm{M}$ FM1-43. The signal at the level of the stereocilia (ם) is a difference signal obtained by subtraction of the mean fluorescence signal in time and age-matched EGTA-treated cultures (obtained 45 min after a 15 min treatment with $5 \mathrm{~mm}$ EGTA) from the mean signal recorded in the sham-treated control cultures. Images were obtained consecutively, and the time base has been adjusted for the interval between frame capture at each level. Data sets from control and EGTAtreated cultures contained samples from 21 hair cells in four different cultures and 30 hair cells in eight different cultures, respectively. 

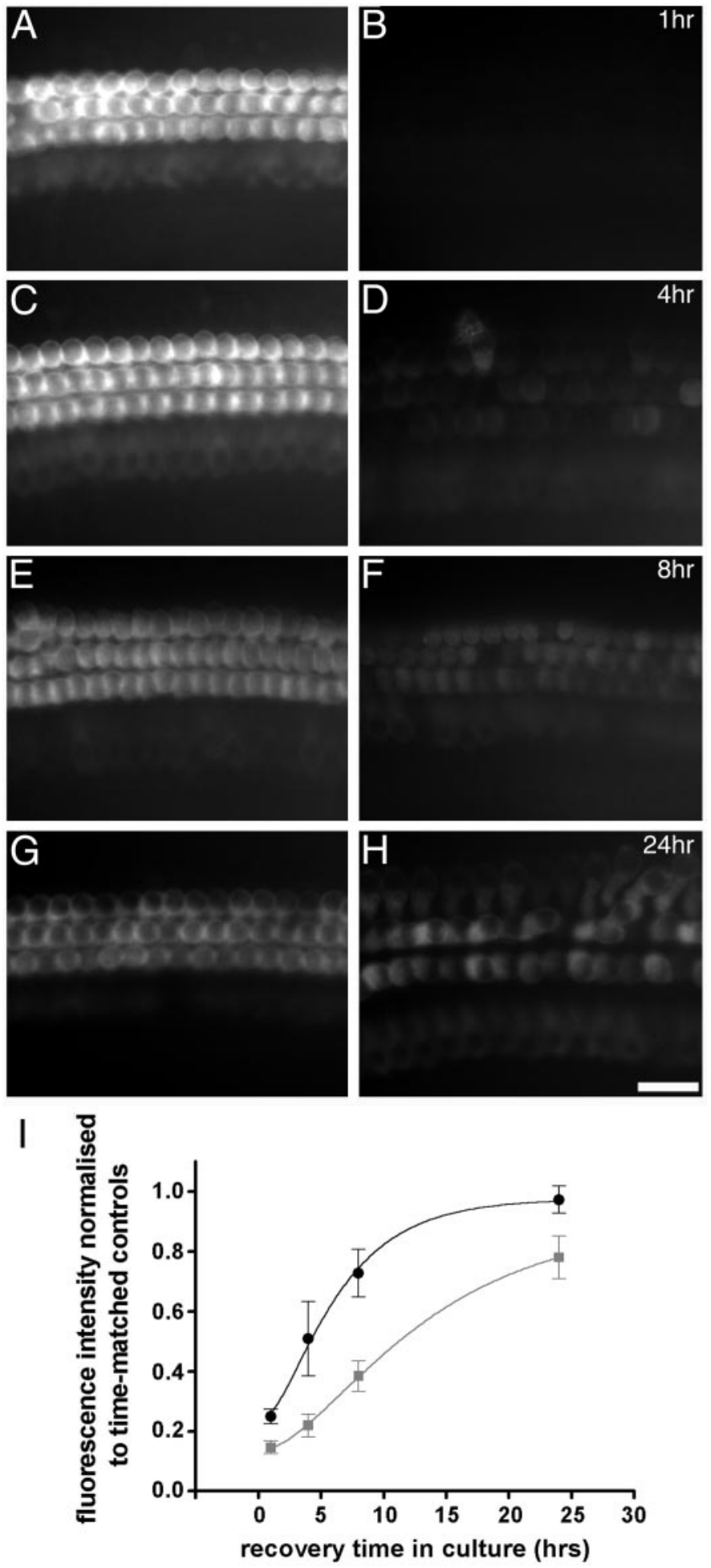

Figure 4. Recovery of FM1-43 dye loading after calcium chelation. $A, C$, $E, G$, Images of control, HBHBSS-treated basal-coil cultures after $1,4,8$, and $24 \mathrm{hr}$, respectively. Images were captured $10 \mathrm{~min}$ after a $10 \mathrm{sec}$ bath application of $3 \mu \mathrm{M}$ FM1-43. $B, D, F, H$, Images of basal-coil cultures incubated in HBHBSS containing $5 \mathrm{~mm}$ EGTA for $15 \mathrm{~min}$ and then returned to normal calcium containing culture medium for 1, 4, 8, and 24 $\mathrm{hr}$ (as indicated). Images were captured $10 \mathrm{~min}$ after a $10 \mathrm{sec}$ bath application of $3 \mu \mathrm{M}$ FM1-43. Scale bar (shown in $H$ for $A-H$ ): $25 \mu \mathrm{m}$. $I$, Quantitative assessment of FM1-43 loading. Data are pooled from a minimum of three cultures at each time point. Dye loading recovers to control levels over a $24 \mathrm{hr}$ period. Apical-coil hair cells (-) recover to 95\% of control. Basal-coil hair cells ( $\square$ ) recover more slowly to $80 \%$ of control reversible in both basal-coil ( $n=11$ coils) (Fig. $4 C-H$ ) and apical-coil ( $n=13$ coils; data not shown) hair cells. Quantitative assessment of the amount of loading was obtained by direct comparison with time-matched controls (Fig. 4I). FM1-43 dye loading in apical-coil hair cells recovers to $95 \%$ of control levels over $24 \mathrm{hr}$, whereas loading in basal-coil hair cells recovers to $80 \%$. The time course of dye loading recovery can be fitted by the exponential growth function that has been used to describe the regeneration of tip links in chick hair cells after BAPTA treatment (Zhao et al., 1996). Dye labeling recovers in mouse hair cells with half times derived from fits to the pooled data of 4.5 and $9.6 \mathrm{hr}$ for apical- and basal-coil hair cells, respectively (Fig. 4I).

\section{Myo7a mutant hair cells do not load with FM1-43 unless stimulated mechanically}

Hair cells from mice homozygous for the $M y o 7 a^{6 J}$ mutation transduce, but little or no transducer current is activated at rest (Richardson et al., 1997, 1999). The relation between bundle displacement and transducer current is shifted to the right so that excitatory stimuli of at least $150 \mathrm{~nm}$ are required to open the channels (Fig. 5A). A similar relation is observed in $M y o 7 a^{4626 S B}$ mice (data not shown). We tested whether hair cells in cultures prepared from Myo7a mutant mice label with FM1-43 using bath application of the dye. Loading of FM1-43 in heterozygous $+/ M y o 7 a^{6 J}$ hair cells $(n=5$ basal coils, 4 apical coils) (Fig. 5B,C) is normal and indistinguishable from that observed in wild-type CD1 control cultures. However, dye loading in homozygous Myo $7 a^{6 J} / M y o 7 a^{6 J}$ hair cells is completely abolished $(n=5$ basal coils, 5 apical coils) (Fig. $5 D, E)$. Homozygous $M y o 7 a^{6 J}$ mutant hair cells have disorganized hair bundles. These can be visualized during local perfusion of FM1-43, as the dye partitions into the outer leaflet of the plasma membrane (data not shown), but subsequent intracellular labeling of hair cells is not observed.

To see whether dye loading is related to the state of the transducer channels, we stimulated the bundles of individual hair cells of homozygous $M y o 7 a^{4626 S B}$ mice using a series of large, 2 $\mathrm{sec}$ force steps in the presence of $3 \mu \mathrm{M}$ FM1-43. After a $60 \mathrm{sec}$ period of stimulation, equivalent to a total excitatory stimulus time of $16 \mathrm{sec}$, the stimulated cells were selectively labeled with the dye ( $n=6$ outer hair cells and 4 inner hair cells) (Fig. 6A-F).

\section{Extracellular FM1-43 blocks transducer currents in mouse hair cells}

Interactions of FM1-43 with the mechanotransducer channel were tested by applying the dye while recording transducer currents in response to fluid-jet stimulation (Kros et al., 1992). Perfusion with FM1-43 reduces the currents in a voltagedependent manner, such that block is less effective at large positive and large negative potentials than at intermediate potentials (Fig. $7 A-F$ ). The block by FM1-43 is fully reversible within $10 \mathrm{sec}$ after return to normal extracellular solution. The voltage dependence of the block is clearly noticeable in the currentvoltage curves of Figure 7C. FM1-43 exaggerates the nonlinearity

\footnotetext{
values over this time period. Data for both apical- and basal-coil cultures were fitted with an exponential growth function (fraction of control value $\left.=A+B[1-\exp (-t / \tau)]^{\mathrm{n}}\right)$ with three unconstrained variables: $A$, the fraction of dye loading remaining after calcium chelation; $B$, the increase in dye loading during the time period; and $\tau$, the time constant, as described by Zhao et al. (1996). For $n=2$, fit parameters for apical-coil and basal-coil cells are as follows: for $A, 0.22$ and 0.14 , for $B, 0.74$ and 0.76 , and for $\tau, 4.5$ and $9.6 \mathrm{hr}$, respectively.
} 
A
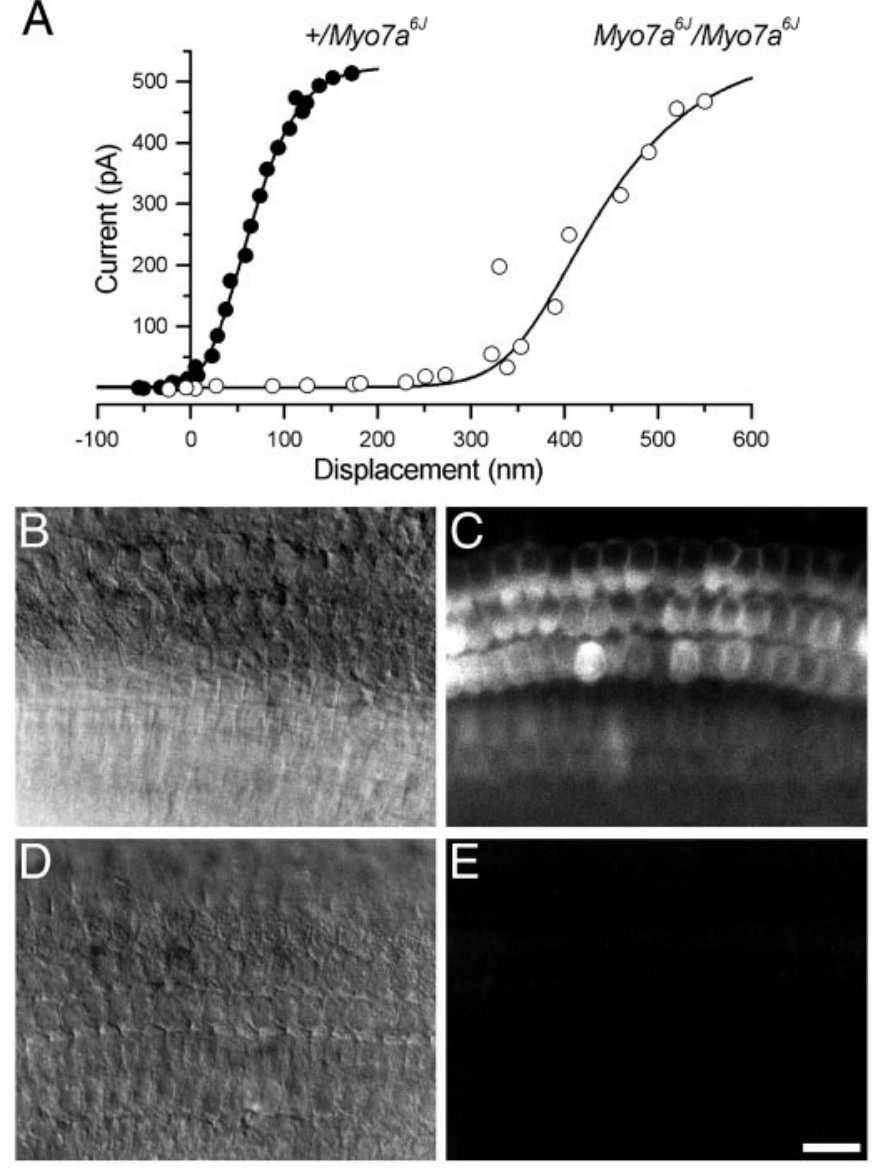

Figure 5. Failure of homozygous Myo7a ${ }^{6 J}$ hair cells to load with FM1-43. $A$, Relationship between maximum transducer current at $-84 \mathrm{mV}$ during a $50 \mathrm{msec}$ force step and hair bundle displacement in heterozygous (P1 culture, $3 \mathrm{~d}$ in vitro) and homozygous (P1 culture, $2 \mathrm{~d}$ in vitro) Myo7a ${ }^{6 J}$ outer hair cells. Note that this relationship is shifted to the right in the homozygote, so that no current is activated in the unstimulated bundle. $B$, $D$, DIC images from the basal coil of cochlear cultures ( $\mathrm{P} 2$ cultures, $1 \mathrm{~d}$ in vitro) from a heterozygous Myo $7 a^{6 J}$ mouse $(B)$ and a homozygous Myo $7 a^{6 J}$ mouse $(D)$ showing the normal arrangement of the three rows of outer and one row of inner hair cells in both cases. $C, E$, Images taken $6 \mathrm{~min}$ after a $10 \mathrm{sec}$ bath application of $3 \mu \mathrm{M}$ FM1-43. The heterozygous hair cells $(C)$ load with the dye, whereas the homozygous hair cells $(E)$ fail to load. Scale bar (shown in $E$ for $B-E$ ): $25 \mu \mathrm{m}$.

of the current-voltage curves that is normally observed for transduction in outer hair cells and has been tentatively explained by a voltage-dependent block caused by divalent cations (Kros et al., 1992). This explanation is consistent with the transducer channel being a nonselective cation channel with a relatively high permeability, but low conductance, for calcium ions (Howard et al., 1988; Ricci and Fettiplace, 1998). The current-voltage curves in the presence or absence of FM1-43 could be fitted with the same simple single-energy-barrier model (Fig. $7 C$, see legend), the main difference being a steeper rectification (i.e., smaller $V_{\mathrm{s}}$ ) with FM1-43. This model assumes that one energy barrier is rate limiting (Jack et al., 1983) and is certainly oversimplified, but it has been applied successfully to the calcium block of cGMPgated channels (Haynes and Yau, 1985). The barrier can be thought of as being associated with one of the binding sites for divalent cations that block permeation of monovalent cations. The fractional distance $\gamma$ of the energy barrier within the electrical field of the membrane (measured from the outside) was
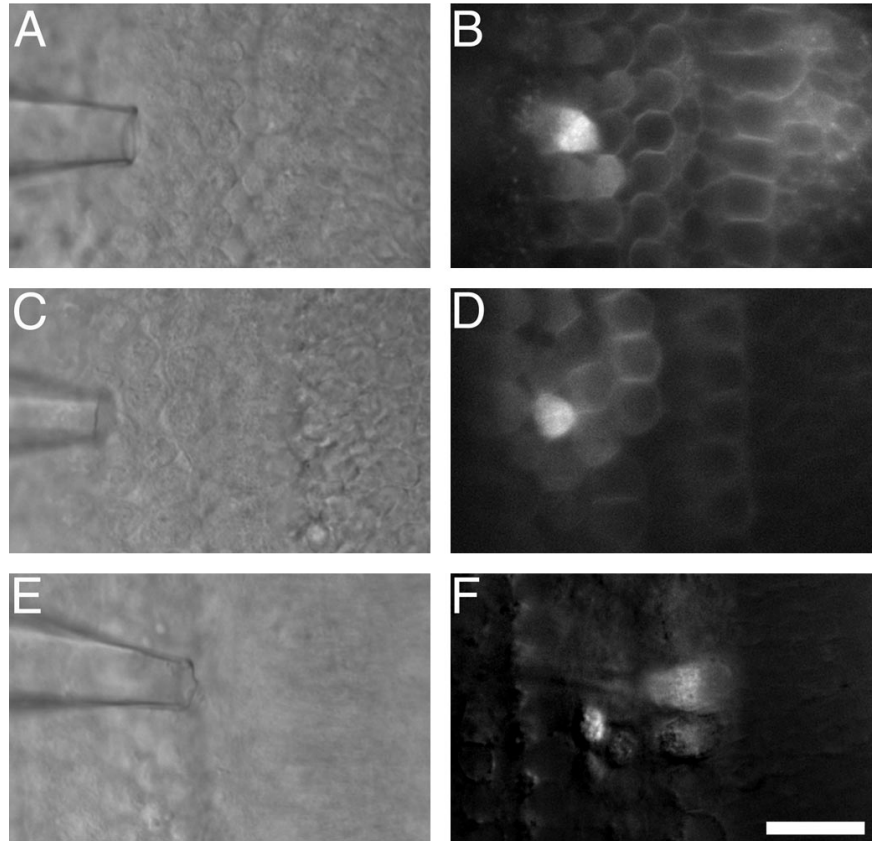

Figure 6. Loading of $3 \mu \mathrm{M}$ FM1-43 in homozygous Myo $7 a^{4626 S B}$ hair cells during hair-bundle stimulation. $A, C, E$, DIC images showing the stimulating pipette placed close to homozygous MyoVIII $A^{4626 S B}$ outer $(A, C)$ and inner $(E)$ hair cells before hair bundle stimulation. The hair bundles were stimulated by fluid flow from the stimulating pipette using alternating, $2 \mathrm{sec}$ inhibitory and excitatory step stimuli for a period of $60 \mathrm{sec} . B$, $D, F$, At the end of the stimulation period a fluorescent image was captured at a focal plane $10 \mu \mathrm{m}$ below the cell surface. A significant increase in the fluorescent signal is observed in the cells that were stimulated. There is also a noticeable signal in some of the hair cells immediately surrounding the stimulating pipette, whereas cells more remote to the pipette do not load with the dye. Scale bar (shown in $F$ for $A-F): 25 \mu \mathrm{m}$.

$0.51 \pm 0.01(n=13)$ in the presence of $1.3 \mathrm{~mm}$ external calcium. Superfusion of FM1-43 at concentrations between 0.3 and $20 \mu \mathrm{M}$ did not significantly change the value of $\gamma$ (one-way ANOVA). For example, in $3 \mu \mathrm{M}$ FM1-43, $\gamma$ was $0.51 \pm 0.02(n=7)$. Dose-response curves for the effect of FM1-43 (Fig. 7D) are thus voltage dependent. The $K_{\mathrm{d}}$ at $+96 \mathrm{mV}(3.0 \mu \mathrm{M})$ is $2.5 \times$ larger than at $-4 \mathrm{mV}$, at which potential the drug is most effective $\left(K_{\mathrm{d}}\right.$ $=1.2 \mu \mathrm{M})$. Hill coefficients ranged from 1.2 to 2.3 , suggesting at least two binding sites for FM1-43. The Hill coefficient varied significantly ( $p<0.0001$, one-way ANOVA) with voltage (Fig. $7 D$ ), being lowest at extreme potentials. Relief from block is larger at extreme positive than at extreme negative potentials (Fig. $7 D, E$ ). The relief from block at both extreme negative and extreme positive potentials, resulting in a bell-shaped dependence of fractional block on potential, is commonly seen as a hallmark of a permeant ionic pore block (Lu and Ding, 1999). For an impermeant cationic pore blocker applied from the extracellular side, one would expect the block to increase monotonically with hyperpolarization as the cation gets more firmly stuck inside the pore. A permeant blocker, on the other hand, would be dislodged from its binding site and forced through the pore toward the cytoplasm at sufficiently hyperpolarized potentials.

The block by FM1-43 is strongly dependent on extracellular calcium, being most effective at low calcium concentrations (Fig. $7 F$ ). At $10 \mathrm{~mm}$ extracellular calcium, $3 \mu \mathrm{M}$ FM1-43 has little or no effect on mechanotransduction. Another notable feature of the block is that, at negative potentials, the resting transducer cur- 
A

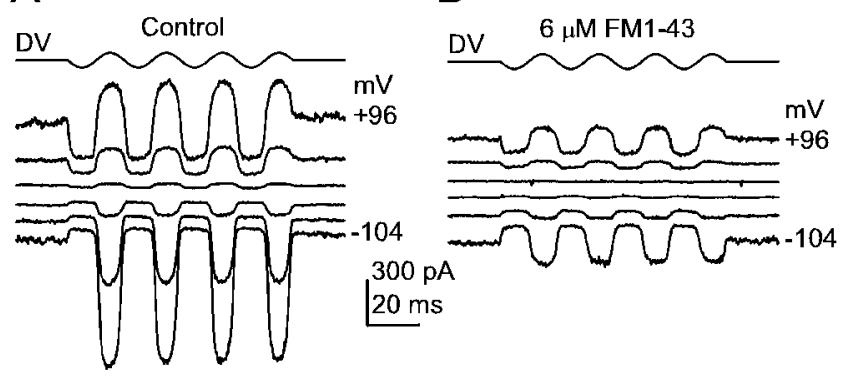

C D
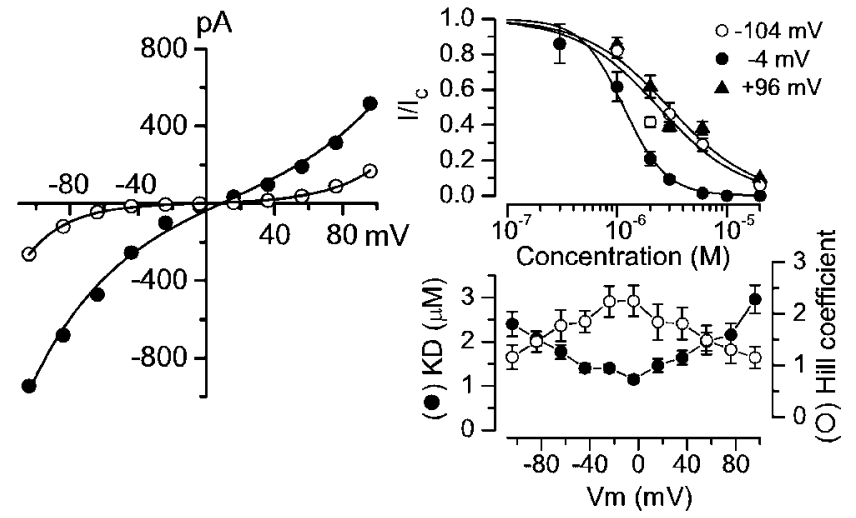

E

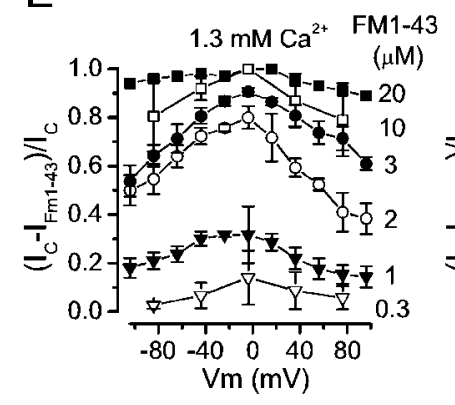

$F$

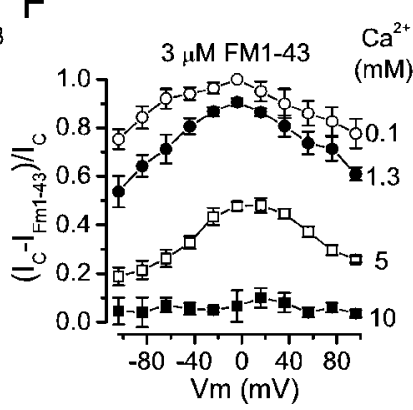

Figure 7. Block of mechanotransduction currents by extracellular FM1-43. $A$, Mechano-electrical transducer currents in a P5 outer hair cell elicited by sinusoidal fluid-jet stimulation at $45 \mathrm{~Hz}$. Driver voltage $(D V)$ to the jet ( $25 \mathrm{~V}$ amplitude) is shown above the currents. The membrane potential was stepped between -104 and $+96 \mathrm{mV}$ in $20 \mathrm{mV}$ increments from a holding potential of $-84 \mathrm{mV}$. For clarity, only responses to every other voltage step are shown. All records are single traces and are offset so that the zero-transducer current levels (responses to inhibitory stimuli) are equally spaced. $B$, Superfusion with $6 \mu \mathrm{M}$ FM1-43 rapidly reduced the transducer currents. Note that more current is shut off in response to the inhibitory phase of the sinusoid at $-104 \mathrm{mV}$, pointing to an increase in the resting transducer current caused by the dye at this potential. $C$, Current-voltage curves for the peak-to-peak transducer currents recorded for the cell in $A$ and $B$. The fits through the data are according to a simple single-energy-barrier model: $I(V)=k[\exp ((1-\gamma)(V-$ $\left.\left.\left.V_{\mathrm{r}}\right) / V_{\mathrm{s}}\right)-\exp \left(-\gamma\left(V-V_{\mathrm{r}}\right) / V_{\mathrm{s}}\right)\right]$, where $k$ is a proportionality constant, $V_{\mathrm{r}}$ is the reversal potential, $V_{\mathrm{s}}$ is a measure for the steepness of the rectification, and $\gamma$ is the fractional distance within the membrane's electrical field of an energy barrier, as measured from the outside. (๑) $k=112 \mathrm{pA}$, $V_{\mathrm{r}}=8.6 \mathrm{mV}, V_{\mathrm{s}}=27 \mathrm{mV}$, and $\gamma=0.52 ;(\bigcirc) k=4 \mathrm{pA}, V_{\mathrm{r}}=-7.0 \mathrm{mV}$, $V_{\mathrm{s}}=13 \mathrm{mV}$, and $\gamma=0.54 . C_{\mathrm{m}}, 5.8 \mathrm{pF} ; R_{\mathrm{s}}, 4.2 \mathrm{M} \Omega ; 24^{\circ} \mathrm{C} . D$, Doseresponse curves for block of transducer currents by FM1-43 at three different membrane potentials (top panel). The data were fitted with a logistic curve: $I / I_{\mathrm{C}}=1 /\left(1+\left([\mathrm{D}] / K_{\mathrm{d}}\right)^{n \mathrm{H}}\right)$, where $I$ is the current in the presence of the dye, $I_{\mathrm{C}}$ is the control current, $K_{\mathrm{d}}=2.4 \pm 0.3 \mu \mathrm{M}(\bigcirc) ; 1.2 \pm$ $0.1 \mu \mathrm{M}(\bullet) ; 3.0 \pm 0.3 \mu \mathrm{M}(\mathbf{\Delta}) . n_{\mathrm{H}}$ (Hill coefficient) $=1.2 \pm 0.2 \mu \mathrm{M}(\bigcirc)$; $2.2 \pm 0.3 \mu \mathrm{M}(\bullet) ; 1.2 \pm 0.2 \mu \mathrm{M}(\mathbf{\Delta})$. Bottom panel, $K_{\mathrm{d}}$ and $n_{\mathrm{H}}$ both vary rent, i.e., the current in the absence of a stimulus, is hardly reduced and can even be increased (Fig. $7 A, B$ ). This may reflect a decreased influx of calcium ions at rest, which leads to an increase in open probability of the channel (Assad et al., 1989; Crawford et al., 1989). All of these findings are consistent with FM1-43 and calcium ions competing for the same binding sites in the channel pore.

Extracellular application of the larger FM1-43 analog, FM3-25, did not affect transducer currents at concentrations up to $30 \mu \mathrm{M}$ over the range of potentials (between -104 and $+96 \mathrm{mV}$ ) tested. When the preparations were observed under fluorescence after $2.5 \mathrm{hr}$ of experimentation with $30 \mu \mathrm{M}$ FM3-25, dye loading into the hair cells was not seen. Under similar conditions, FM1-43 loading was observed in all hair cells.

\section{Kinetics of transducer current block}

We applied experimental protocols designed to test whether the drug can bind to the closed channel or whether the channel has to open first before block can occur. In the latter case, provided the binding kinetics is sufficiently slow to be detectable, transducer current may flow transiently when the open probability of the channel is suddenly increased from near to zero by an excitatory mechanical step, as observed previously for transducer currents in the presence of amiloride and analogs (Rüsch et al., 1994). This may also give rise to the phenomenon of use-dependent block, where repeated opening and closing of the channels leads to a progressive increase of the block and reduction of the current (Courtney, 1975). Neither of these phenomena is observed for the block by $3 \mu \mathrm{M}$ FM1-43 (Fig. $8 A, B$ ). Instead, transducer currents at negative potentials develop more slowly in the presence of FM1-43 than those in controls (Fig. $8 B-D$ ). Fitted time constants were voltage dependent, speeding up with hyperpolarization (Fig. $8 C)$. The most likely explanation for this is that it represents competition between FM1-43 and other cations for binding sites inside the channel pore, whereby the influx of cations after an excitatory step reduces the block with a time constant that speeds up with increasing kinetic energy of the cations. There is no obvious slowing of the kinetics during inhibitory steps (Fig. $8 B, D)$, which suggests that the channels can close with the drug bound or that the unbinding kinetics is faster than normal channel closure. The lack of evidence for open-channel block or use dependence of the block suggests that FM1-43 can be bound to either the open or the closed channel. Alternatively FM1-43 may bind only to the open state, but in that case the kinetics is faster than the mechanical step.

The kinetics of the onset and release of block by $3 \mu \mathrm{M}$ FM1-43 was also examined by applying voltage jumps during an excitatory mechanical step (Fig. 8E,F), taking advantage of the voltage dependence of the block and the more rapid time constants of the voltage steps $(\sim 30 \mu \mathrm{sec})$ compared with the mechanical steps $(140 \mu \mathrm{sec})$. For the cell shown in Figure $8 E$, a voltage jump from -44 to $-104 \mathrm{mV}$ causes a reduction of the block with a time constant of 2.7 msec. Jumping the voltage back to $-44 \mathrm{mV}$ increases the block (Fig. $8 E$ ), but the time course of drug binding

$\leftarrow$

significantly as a function of voltage $(p<0.0001$, ANOVA). $E$, Voltage dependence of the block of FM1-43 in the presence of $1.3 \mathrm{mM}$ extracellular calcium. The ordinate represents fractional block, from 0 (no block) to 1 (complete block). For $D, E: 0.3,1$, and $2 \mu \mathrm{M}, n=3 ; 3 \mu \mathrm{M}, n=8 ; 6$ $\mu \mathrm{M}, n=4 ; 10 \mu \mathrm{M}, n=2 ; 20 \mu \mathrm{M}, n=1 . F$, Calcium sensitivity of block of the transducer currents by $3 \mu \mathrm{M}$ FM1-43. For $0.1 \mathrm{mM} \mathrm{Ca}^{2+}, n=3 ; 1.3 \mathrm{mM}$, $n=8 ; 5 \mathrm{mM}, n=5 ; 10 \mathrm{mM}, n=2$. 
A

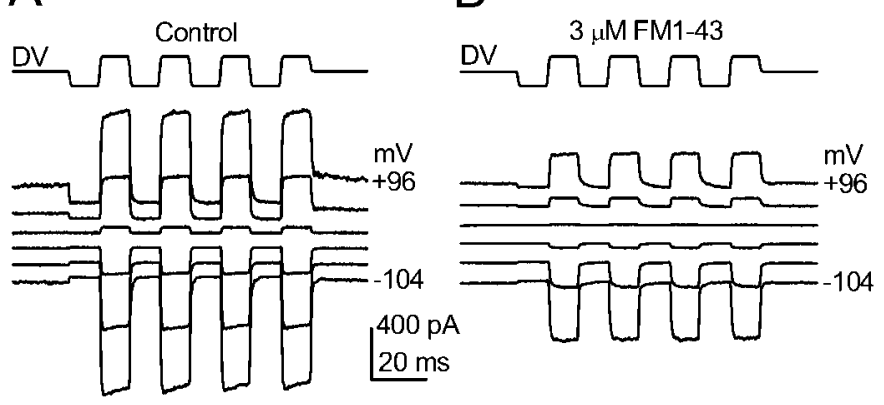

C
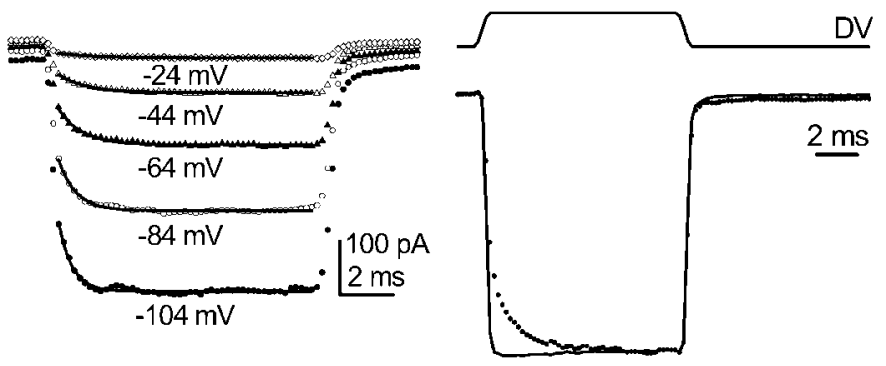

$E$
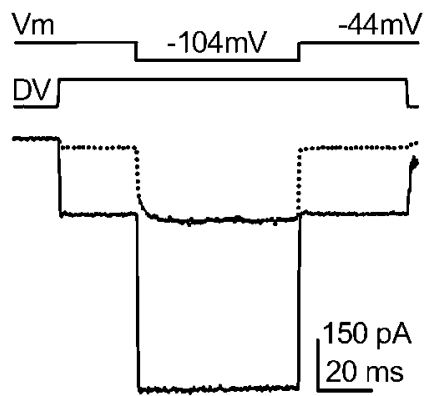

$\mathrm{F}$

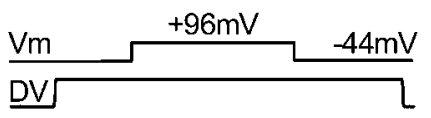

DV

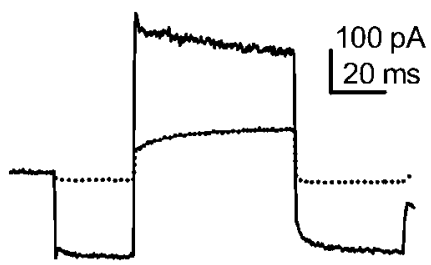

Figure 8 . Kinetics of mechanotransduction block by $3 \mu \mathrm{M}$ FM1-43. $A$, Transducer currents in a P7 outer hair cell in response to a series of saturating excitatory and inhibitory steps of $11 \mathrm{msec}$ duration. Driver voltage $( \pm 25 \mathrm{~V})$ shown above the traces. The membrane potential was stepped between -104 and $+96 \mathrm{mV}$ in $20 \mathrm{mV}$ increments from a holding potential of $-84 \mathrm{mV}$. For clarity, only every other trace is shown. Current recordings are averages of three stimulus presentations and are offset so that zero-transducer current levels are equally spaced. $B$, Currents in the same cell in the presence of FM1-43, averaged from seven stimuli. Driver voltage \pm 25 V. $C$, Single-exponential fits to responses to excitatory steps between -24 and $-104 \mathrm{mV}$. Same experiment as in $B$, but all recorded voltage levels are shown. Responses to the four repetitions of the excitatory steps were superimposed and averaged. Time constants of the fits at the different potentials are as follows: $-24 \mathrm{mV}, 1.31 \mathrm{msec} ;-44 \mathrm{mV}, 1.11$ msec; $-64 \mathrm{mV}, 0.88 \mathrm{msec} ;-84 \mathrm{mV}, 0.66 \mathrm{msec} ;-104 \mathrm{mV}, 0.51 \mathrm{msec} . C_{\mathrm{m}}$, $6.7 \mathrm{pF} ; R_{\mathrm{s}}, 5.3 \mathrm{M} \Omega ; 25^{\circ} \mathrm{C}$. In $A-C$, mechanical steps were filtered at 0.5 $\mathrm{kHz}$. $D$, Transducer currents in another outer hair cell (P7) in response to saturating excitatory and inhibitory mechanical stimuli $( \pm 25 \mathrm{~V}$ driver voltage), shown above. Holding potential, $-84 \mathrm{mV}$. Currents (averaged from 5 repetitions) before (solid trace) and during (dotted trace) superfusion of FM1-43 were scaled and superimposed. Note that FM1-43 slows the kinetics on the excitatory step (time constant $1.1 \mathrm{msec}$ ) but has no noticeable effect on the kinetics after the inhibitory step. Maximum transducer current was $-566 \mathrm{pA}$ before and $-240 \mathrm{pA}$ during FM1-43 application. $C_{\mathrm{m}}, 5.2 \mathrm{pF} ; R_{\mathrm{s}}, 7.1 \mathrm{M} \Omega ; 24^{\circ} \mathrm{C}$. $E$, Voltage jump experiment in a P7 outer hair cell, before (solid trace, 10 averages) and during (dotted trace, 8 averages) FM1-43 superfusion. The stimulus protocol is shown above. Holding potential, $-44 \mathrm{mV}$, jump to $-104 \mathrm{mV}$. Time constant of fit, 2.7 msec. $C_{\mathrm{m}}, 6.7 \mathrm{pF} ; R_{\mathrm{s}}, 5.3 \mathrm{M} \Omega ; 25^{\circ} \mathrm{C} . F$, Voltage-jump experiment
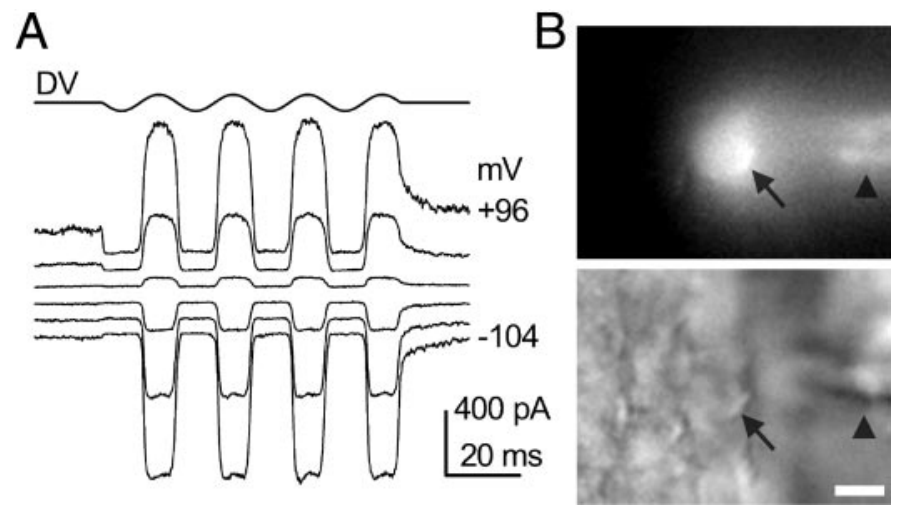

Figure 9. Intracellular perfusion of FM1-43 dye. $A$, Large mechanoelectrical transducer currents of a wild-type CD-1 outer hair cell (P6) recorded $4 \mathrm{~min}$ after establishing the whole-cell configuration with $20 \mu \mathrm{M}$ FM1-43 in the patch pipette. The membrane potential was stepped between -104 and $+96 \mathrm{mV}$ in $40 \mathrm{mV}$ increments from a holding potential of $-84 \mathrm{mV}$. All records are single traces and are offset so that the zero-transducer current levels (responses to inhibitory stimuli) are equally spaced. $B$, Hair-bundle labeling in a homozygous mutant Myo7a $a^{4626 S B}$ outer hair cell in whole-cell communication with a patch-pipette containing $20 \mu \mathrm{M}$ FM1-43. Top panel, Fluorescence image captured 2 min after patch rupture. Note the presence of dye in the hair bundle of the mutant hair cell (arrow). The patch pipette is indicated by the arrowhead. Bottom panel, Corresponding DIC image showing the hair bundle (arrow) and out-of-focus patch pipette (arrowhead). Scale bar, $5 \mu \mathrm{m}$.

is still too fast to be resolved, indicating that the block develops with a time constant faster than that of the voltage clamp. In six cells, the time constant for the release of the block on jumping from -44 to $-104 \mathrm{mV}$ was $3.0 \pm 0.3 \mathrm{msec}$. Voltage jumps from -44 to $+96 \mathrm{mV}$ (Fig. $8 F$ ) were studied in two cells. Release of the block at $+96 \mathrm{mV}$ proceeded more slowly than at $-104 \mathrm{mV}$, with the time constants for the two cells being 13.8 and $12.6 \mathrm{msec}$.

\section{Effects of intracellularly applied FM1-43}

FM1-43 was included in the patch pipette to assess its effect on transducer currents when applied from the intracellular side. Transducer currents were recorded as for the experiments in which the drug was applied extracellularly. Concentrations of 6 and $20 \mu \mathrm{M}$, which block $\sim 75$ and $95 \%$, respectively, of the transducer current at $-84 \mathrm{mV}$ when applied from the outside, were tested first. No appreciable changes in size of the transducer currents occurred during recordings that lasted up to 5 min after establishing the whole-cell configuration (Fig. 9A). Mean maximum transducer currents at $-84 \mathrm{mV}$ were $-514 \pm 27 \mathrm{pA}(n=4$ cells $)$ and $-625 \pm 22 \mathrm{pA}(n=5$ cells $)$ with 6 and $20 \mu \mathrm{M}$ intracellular FM1-43, respectively. These means are not significantly different (ANOVA) from those in controls with normal intracellular solution $(-578 \pm 26 \mathrm{pA} ; n=15$ cells $)$. In two cells with $50 \mu \mathrm{M}$ FM1-43 in the patch pipette, currents after 1-2 min were -381 and $-593 \mathrm{pA}$, respectively, at $-84 \mathrm{mV}$. Higher concentrations (100-200 $\mu \mathrm{M})$ proved incompatible with maintaining whole-cell recordings for more than a few seconds. Estimating an

$\leftarrow$

in another outer hair cell (P7). Holding potential, $-44 \mathrm{mV}$, jump to +96 $\mathrm{mV}$. Solid line $=$ control, 4 repetitions; dotted line $=$ FM1-43, 10 repetitions. Fit time constant, 13.8 msec. $C_{\mathrm{m}}, 6.1 \mathrm{pF} ; R_{\mathrm{s}}, 4.6 \mathrm{M} \Omega ; 24^{\circ} \mathrm{C}$. In $E$ and $F$, electrical stimuli and combinations of mechanical and electrical stimuli were alternated. Responses to electrical stimuli alone were subtracted from combinations of both stimuli to eliminate linear leak and voltagedependent currents. 

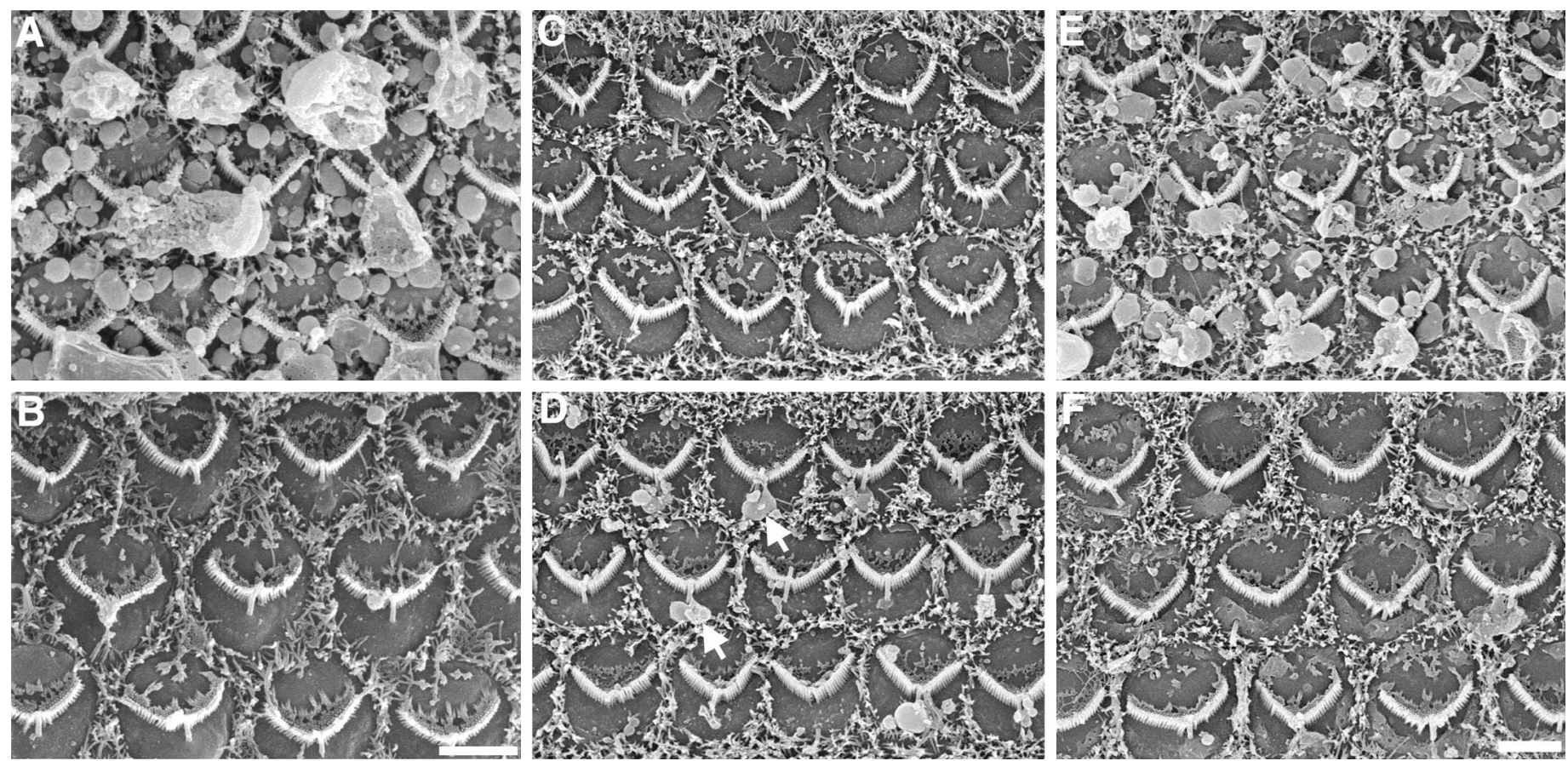

Figure 10. Protection from aminoglycoside damage by calcium chelation and FM1-43. $A, B$, Scanning electron micrographs showing the apical surfaces of outer hair cells from the basal ends of apical-coil cultures after exposure to $1 \mathrm{~mm}$ neomycin for $1 \mathrm{hr}$. The outer hair cells in cultures that were pretreated with HBHBSS alone for 10 min before aminoglycoside exposure $(A)$ exhibit extensive blebbing at the cell surface. The outer hair cells in cultures that were pretreated with $5 \mathrm{~mm}$ BAPTA for $10 \mathrm{~min}$ before aminoglycoside exposure in the presence of calcium $(B)$ do not exhibit surface blebbing. $C-F$, Scanning electron micrographs showing the apical surfaces of outer hair cells from basal-coil cultures. Outer hair cells in control cultures incubated in HBHBSS for a total time of $70 \mathrm{~min}(C)$ have a normal appearance. In cultures that have been exposed to $30 \mu \mathrm{M}$ FM1-43 for 70 min $(D)$, surface blebbing (arrows) is observed around the base of the kinocilium in some of the outer hair cells. In cultures that have been exposed to 1 mm neomycin for 60 min after a 10 min preincubation in HBHBSS $(E)$, extensive blebbing and disruption of the apical surface is apparent. Outer hair cells in cultures that have been preincubated in $30 \mu \mathrm{M}$ FM1-43 for 10 min followed by 60 min exposure to 1 mM neomycin in the presence of $30 \mu \mathrm{M}$ FM1-43 $(F)$ are protected from the ototoxic effects of the aminoglycoside antibiotic. Scale bars (shown in $B$ for $A, B$ and in $F$ for $C-F$ ): $3 \mu \mathrm{m}$.

aqueous diffusion coefficient for FM1-43 of $\sim 5 \times 10^{-6} \mathrm{~cm}^{2} / \mathrm{sec}$ (Weiss, 1996), we expect the unbound dye to equilibrate with the cytoplasm with a time constant of $\sim 7 \mathrm{sec}$ (Oliva et al., 1988). Homozygous $M y o 7 a^{4626 S B}$ hair cells were used to confirm that dye does reach the stereocilia when applied via the patch pipette at the base of the cell because it was known that these cells would not load with any dye that might inadvertently leak from the patch pipette before making a seal with the cell. When FM1-43 is loaded through the patch pipette, stereocilia labeling is observed within $1 \mathrm{~min}$ of whole-cell recording (Fig. 9B). These results indicate that FM1-43 in concentrations up to $50 \mu \mathrm{M}$ does not block transducer currents when applied intracellularly and may point to differences in the electrical charge distribution around, or the topology of, the intracellular and extracellular sides of the channel.

\section{Aminoglycoside-induced damage is reduced by calcium chelation and the presence of FM1-43}

Two experiments were performed to test whether aminoglycoside antibiotics and FM1-43 share the same entry pathway in hair cells. First we assessed whether a 10 min pretreatment step with $5 \mathrm{~mm}$ BAPTA would reduce the effects of exposure to $1 \mathrm{~mm}$ neomycin. Second we tested whether preincubation in 3 or $30 \mu \mathrm{M}$ FM1-43 dye followed by treatment with $1 \mathrm{~mm}$ neomcyin in the continued presence of FM1-43 dye could block the ototoxic effect of neomycin. Numerous blebs form at the surface of the outer hair cells as a result of exposure to $1 \mathrm{~mm}$ neomycin for $1 \mathrm{hr}$ at room temperature ( $n=7$ basal coils, 5 apical coils) (Fig. 10A). In contrast, outer hair cells are protected from aminoglycoside damage in cultures in which the calcium has been chelated for $10 \mathrm{~min}$ before aminoglycoside exposure ( $n=6$ basal coils, 6 apical coils $)$ (Fig. 10B). Protection from aminoglycoside damage by pretreatment with BAPTA is almost complete (i.e., as in Fig. 10B) for cells in the basal end of apical-coil cultures. BAPTA pretreatment does not protect all hair cells in the basal-coil cultures. A comparison of control cultures ( $n=7$ basal coils, 7 apical coils $)$ (Fig. 10C) and cultures exposed to FM1-43 at a concentration of $30 \mu \mathrm{M}(n=7$ basal coils, 7 apical coils) (Fig. $10 D)$ or $3 \mu \mathrm{M}(n=$ 4 basal coils, 4 apical coils) (data not shown) indicates that continued exposure to FM1-43 (70 min) causes some membrane blebbing at the apex of basal-coil outer hair cells. However, this effect is mild relative to the effects of $1 \mathrm{~mm}$ neomycin $(n=7$ basal coils, 7 apical coils) (Fig. 10E). A comparison of the surface morphology observed when $1 \mathrm{~mm}$ neomycin is applied in the presence of $30 \mu \mathrm{M}$ FM1-43 ( $n=7$ basal coils, 7 apical coils) (Fig. $10 F$ ) indicates that the effects of FM1-43 and neomycin are clearly not additive and that FM1-43 dye provides a significant attenuation of neomycin-induced hair-cell surface damage. With outer hair cells in the basal ends of apical-coil cultures prepared from $1 \mathrm{~d}$ postnatal mice, $30 \mu \mathrm{M}$ FM1-43 had no effect on the surface morphology and also provided virtually complete protection from the effects of $1 \mathrm{~mm}$ neomycin. A slight reduction in the severity of the neomycin effect was also noted in the presence of $3 \mu \mathrm{M}$ FM1-43. 


\section{DISCUSSION}

Real-time confocal microscopy provides firm evidence for a rapid, apically located entry mechanism for FM1-43 in mouse cochlear hair cells. A considerable number of coated pits are associated with the apical membrane of the hair cell (Forge and Richardson, 1993; Hasson et al., 1997; Kachar et al., 1997; Richardson et al., 1997; Seiler and Nicolson, 1999), although not with the plasma membrane ensheathing the actin cores of the stereocilia. The time course for receptor-mediated endocytosis via clathrin-coated pits is in the order of minutes, not seconds (for review, see Henkel and Almers, 1996). Thus the speed of FM1-43 dye entry measured in this study argues against uptake via a classical, clathrincoated pit, endocytotic mechanism at the apical surface of the hair cell. Furthermore, after subtraction of the transient signal that is assumed to result from dye partitioning into and out of the outer leaflet of the stereocilial membrane, dye is observed in the stereocilia just before it is seen in the apical pole of the hair cell. This indicates that the dye first enters the cell from the stereocilia. Although rapid endocytotic mechanisms with time constants in the order of seconds or less have been described for neuronal (Klingauf et al., 1998) and secretory (Smith and Neher, 1997) cells, these are usually closely coupled to exocytosis or a stimulus that raises intracellular free calcium (Thomas et al., 1994; Artalejo et al., 1995; Henkel and Almers, 1996). Calcium influx via the transducer channel could provide such an increase in intracellular free calcium, but the block of FM1-43 labeling observed with high extracellular calcium is not consistent with this hypothesis.

A number of lines of evidence suggest that FM1-43 dye enters into mouse cochlear hair cells directly via the transduction channel. First, the dye blocks the mechanotransducer channel from the extracellular side. FM1-43 is one of the most effective blockers known of the mechanotransducer channel, with the voltagedependent $K_{\mathrm{d}}$ varying between 1 and $3 \mu \mathrm{M}$ in the presence of 1.3 $\mathrm{mm}$ extracellular calcium. The sigmoidal voltage dependence of the FM1-43 block is remarkably similar to the permeant block by calcium ions described for other nonselective cation channels such as the cyclic nucleotide-gated channels of cone photoreceptors and olfactory sensory neurons (Frings et al., 1995; Haynes, 1995; Dzeja et al., 1999) and indeed the transducer channel itself (Kros et al., 1992). Such behavior is also found for voltage-gated L-type calcium channels, which can be considered as nonselective cation channels with an extremely high permeability for calcium ions (Tsien et al., 1987). Block by FM1-43 also resembles the permeant block by polyamines of glutamate receptors (Koh et al., 1995; Bähring et al., 1997) and cyclic nucleotide-gated channels from retinal rods (Lu and Ding, 1999). Like FM1-43, polyamines are elongated organic cations. The voltage dependence of the Hill coefficient for FM1-43 block may be caused by ionic interactions in the pore. The minimum of two binding sites for calcium and FM1-43 suggested by the range of Hill coefficients of FM1-43 binding is consistent with a popular model used for describing permeation in L-type calcium channels (Tsien et al., 1987) and also with a more recent model that successfully describes calcium permeation with three binding sites: one high-affinity site flanked by two low-affinity sites (Dang and McCleskey, 1998). Competition between FM1-43 and calcium for calcium-binding sites within the channel would explain why elevated extracellular calcium blocks FM1-43 dye entry. Our observations on the kinetics of block by FM1-43, in response to either mechanical or voltage steps, provide no evidence for an open-channel blocking mecha- nism such as that described previously for block of the mechanotransducer channel by pyrazinecarboxamides (Rüsch et al., 1994). This does not exclude the possibility that the drug can only bind to the open channel, but in that case the kinetics of binding and release must be faster than that of the step stimuli used $(\sim 30 \mu \mathrm{sec}$ for the voltage steps). The slow release of the block, which occurs on a millisecond time scale both on opening more channels mechanically or by stepping the voltage to a potential at which block is less effective, suggests competition between FM1-43 and permeant cations for the binding site. This competition is, as would be expected, voltage dependent with time constants speeding up at extreme potentials and occurs at both positive and negative potentials, providing further evidence for FM1-43 being a permeant blocker.

A second argument for dye entry via the channel is that loading is blocked by pretreating cells with calcium chelators, a condition known to break tip links and prevent channel gating. The block of dye loading observed after calcium chelation takes time to develop completely, indicating that a few of the transducer channels may initially remain open after tip-link breakage, as has been suggested for mature guinea-pig outer hair cells by Meyer et al. (1998). Dye loading is not just blocked by calcium chelation; it also recovers after calcium chelation with a time course similar to that reported for tip-link regeneration in chick hair cells after BAPTA treatment (Zhao et al., 1996). Third, the difference in dye accumulation observed in adjacent inner and outer hair cells (threefold greater in outer hair cells) for a nonsaturating application step $(10 \mathrm{sec})$ correlates fairly well with the ratio of the maximum transduction current that can be elicited from the two cell types. The currents recorded in outer hair cells in cultures of the early postnatal mouse cochlea are more than twice as large as those recorded in inner hair cells (Kros et al., 1992; Kros, 1996). Differences in the percentage of total channels open at rest in the two cell types may account for why the correlation is not perfect. Fourth, hair cells in Myo7a mutant cultures, which can transduce but are known to have all channels closed at rest (Richardson et al., 1997, 1999), do not label with FM1-43. Fifth, and finally, hair cells in Myo7a mutant cultures will load with dye if their hair bundles are stimulated by an excitatory stimulus that is sufficiently large to open the channels that are normally closed at rest in these mutant hair cells. These independent observations provide strong evidence that FM1-43 is entering hair cells directly via the transducer channel. Estimates of the molecular dimensions of FM1-43 (J. Seddon, personal communication) suggest that it would be capable of passing through the channel pore. Although the molecular weight of the FM1-43 cation (451) is greater than that of compounds that are known to pass through the channel (e.g., tetraethylammonium ion, MW 130), it is an elongated linear molecule and it is the diameter of the ethyl and butyl end groups $(\sim 0.78 \times 0.5$ $\mathrm{nm}$ ), as determined when the molecule is viewed down its narrowest axis, which will limit its ability to pass through the channel. The ethyl and butyl end groups of FM1-43 should pass through a similar size pore, and the triethylammonium end group of FM1-43 is similar in size to the tetraethylammonium ion $(0.7 \mathrm{~nm})$ (Howard et al., 1988), an organic cation that is known to pass through the transducer channel with a permeability of 0.17 relative to that of $\mathrm{Cs}^{+}$(Ohmori, 1985). The ineffectiveness of the FM3-25 cation (MW 843) as a blocker is likely to be attributable to conformational disorder in the two long octadecyl chains, which will tend to give them a larger cross-sectional area than the butyl chains of FM1-43 (J. Seddon, personal communication).

The temperature dependence of FM1-43 labeling may suggest 
that the dye is not simply diff using through the channel. However, the set point or open probability of the transducer channel of the hair cell is thought to be maintained by a myosin motor that maintains sufficient tension in the channel/tip-link complex via an active interaction with the actin core of the stereocilium (Gillespie and Corey, 1997). The temperature dependence of the open probability of the transducer channel is not yet known, but it is possible that the myosin ATPase that is responsible for maintaining the set point is temperature sensitive and that most channels are closed at low temperature in mammalian hair cells.

There are a striking number of similarities between the characteristics of FM1-43 dye loading and the mechanisms of aminoglycoside accumulation or toxicity in mouse cochlear cultures. The accumulation of $\left[{ }^{3} \mathrm{H}\right]$-gentamicin in cochlear hair cells and the morphological effects of neomycin are considerably reduced at low temperature $\left(4^{\circ} \mathrm{C}\right)$ and absent in Myo $7 a$ mutants (Richardson et al., 1997). The morphological effects of neomycin also manifest themselves rapidly. They can be blocked by elevated extracellular calcium (Richardson and Russell, 1991) and, as shown in this study, can be prevented by pretreatment with calcium chelators. Furthermore, a gradient of sensitivity to neomycin from base to apex of the cochlea, similar to that observed for FM1-43 dye loading, is also seen in cochlear cultures (Richardson and Russell, 1991). Finally, FM1-43 is able to reduce the ototoxic effect of neomycin, indicating that the two compounds compete for the same entry mechanism. These observations, combined with the evidence presented above, suggest that FM1-43 and aminoglycoside antibiotics may both enter hair cells via the transducer channel. The latter possibility has been suggested previously (Kroese et al., 1989). The finding that FM1-43 does not block the channel from the interior of the cell at concentrations where it blocks strongly from the extracellular side reveals that it passes preferentially in one direction. If the same holds for the aminoglycoside antibiotics, it would explain why both FM1-43 and aminoglycosides accumulate in hair cells and do not unload after exposure. The known differential sensitivity of various hair-cell types to aminoglycoside antibiotics may also be explained by differences in channel open probability at rest. Basal-coil outer hair cells in the mammalian cochlea are among the most sensitive to aminoglycoside damage (Hawkins, 1976), and there is evidence that in vivo they maintain their hair bundles biased with $50 \%$, as opposed to the more usual $5-10 \%$, of their transducer channels open at rest (Russell and Kössl, 1992).

In conclusion, the results of this study provide strong evidence that FM1-43 enters the apical pole of sensory hair cells in the mammalian cochlea via the mechanotransducer channel and suggest that the ototoxic aminoglycoside antibiotics may share the same entry pathway.

\section{REFERENCES}

Artalejo CR, Henley JR, McNiven MA, Palfrey HC (1995) Rapid endocytosis coupled to exocytosis in adrenal chromaffin cells involves $\mathrm{Ca}^{2+}$, GTP, and dynamin but not clathrin. Proc Natl Acad Sci USA 92:8328-8332.

Assad JA, Hacohen N, Corey DP (1989) Voltage dependence of adaptation and active bundle movement in bullfrog saccular hair cells. Proc Natl Acad Sci USA 86:2918-2922.

Bähring R, Bowie D, Benveniste M, Mayer ML (1997) Permeation and block of rat GluR6 glutamate receptor channels by internal and external polyamines. J Physiol (Lond) 502:575-589.

Betz WJ, Bewick GS (1992) Optical analysis of synaptic vesicle recycling at the frog neuromuscular junction. Science 255:200-203.

Betz WJ, Mao F, Bewick GS (1992) Activity dependent fluorescent staining and destaining of living vertebrate motor nerve terminals. J Neurosci 12:363-375.
Betz WJ, Mao F, Smith CB (1996) Imaging exocytosis and endocytosis. Curr Opin Neurobiol 6:365-371.

Cochilla AJ, Angelson JK, Betz WJ (1999) Monitoring secretory membrane with FM1-43 fluorescence. Annu Rev Neurosci 22:1-10.

Courtney KR (1975) Mechanism of frequency-dependent inhibition of sodium currents in frog myelinated nerve by the lidocaine derivative GEA 968. J Pharmacol Exp Ther 195:225-236.

Crawford AC, Evans MG, Fettiplace R (1989) Activation and adaptation of transducer currents in turtle hair cells. J Physiol (Lond) 419:405-434.

Dang TX, McCleskey EW (1998) Ion selectivity through stepwise changes in binding affinity. J Gen Physiol 111:185-193.

Dzeja C, Hagen V, Kaupp UB, Frings S (1999) $\mathrm{Ca}^{2+}$ permeation in cyclic nucleotide-gated channels. EMBO J 18:131-144.

Ernest S, Rauch G-J, Haffter P, Geisler R, Petit C, Nicolson T (2000) Mariner is defective in myosin VIIA: a zebrafish model for human hereditary deafness. Hum Mol Genet 9:2189-2196.

Forge A, Richardson GP (1993) Freeze fracture analysis of apical membranes in cochlear cultures: differences between basal and apical-coil outer hair cells and effects of neomycin. J Neurocytol 22:854-867.

Frings S, Seifert R, Godde M, Kaupp UB (1995) Profoundly different calcium permeation and blockage determine the specific function of distinct cyclic nucleotide-gated channels. Neuron 15:169-179.

Gale JE, Meyers JR, Corwin JT (2000) Solitary hair cells are distributed throughout the extra-macular epithelium in the bullfrog's saccule. J Assoc Res Otolaryngol 1:172-182.

Gillespie PG, Corey DP (1997) Myosin and adaptation by hair cells. Neuron 19:955-958.

Hasson T, Gillespie PG, Garcia JA, Macdonald RB, Zhao Y, Yee AG, Mooseker MS, Corey DP (1997) Unconventional myosins in inner-ear sensory epithelia. J Cell Biol 137:1287-1307.

Hawkins JE (1976) Drug ototoxicity. In: Handbook of sensory physiology, Vol 5 (Keidel WD, Neff WD eds), pp 707-748. Berlin: Springer.

Haynes L, Yau K-W (1985) Cyclic GMP-sensitive conductance in outer segment membrane of catfish cones. Nature 317:61-64.

Haynes LW (1995) Permeation and block by internal and external divalent cations of the catfish cone photoreceptor cGMP-gated channel. J Gen Physiol 106:507-523.

Henkel AW, Almers W (1996) Fast steps in exocytosis and endocytosis studied by capacitance measurements in endocrine cells. Curr Opin Neurobiol 6:350-357.

Howard J, Roberts WM, Hudspeth AJ (1988) Mechanoelectrical transduction by hair cells. Annu Rev Biophys Biophys Chem 17:99-124.

Jack JJB, Noble D, Tsien RW (1983) Electric current flow in excitable cells. Oxford: Oxford UP.

Kachar B, Battaglia A, Fex J (1997) Compartmentalized vesicular traffic around the hair cell cuticular plate. Hear Res 107:102-112.

Klingauf J, Kavalali ET, Tsien RW (1998) Kinetics and regulation of fast endocytosis at hippocampal synapses. Nature 394:581-585.

Koh DS, Burnashev N, Jonas P (1995) Block of native $\mathrm{Ca}^{2+}$-permeable AMPA receptors in rat brain by intracellular polyamines generates double rectification. J Physiol (Lond) 486:305-312.

Kroese ABA, Das A, Hudspeth AJ (1989) Blockage of the transduction channels of hair cells in the bullfrog's sacculus by aminoglycoside antibiotics. Hear Res 37:203-217.

Kros CJ (1996) Physiology of mammalian cochlear hair cells. In: The cochlea (Dallos P, Popper AN, Fay RR, eds), pp 318-385. New York: Springer.

Kros CJ, Rüsch A, Richardson GP (1992) Mechano-electrical transducer currents in hair cells of the cultured neonatal mouse cochlea. Proc R Soc Lond B Biol Sci 249:185-193.

Lu Z, Ding L (1999) Blockade of a retinal cGMP-gated channel by polyamines. J Gen Physiol 113:35-43.

Meyer J, Furness DN, Zenner HP, Hackney CM, Gummer AW (1998) Evidence for opening of hair-cell transducer channels after tip-link loss. J Neurosci 18:6748-6756.

Nicolson T, Rüsch A, Friedrich RW, Granato M, Ruppersberg JP, Nüsslein-Volhard C (1998) Genetic analysis of vertebrate sensory hair cell mechanosensation: the zebrafish circler mutants. Neuron 20:271-283.

Nishikawa S, Sasaki F (1996) Internalization of styryl dye FM1-43 in the hair cells of lateral line organs in Xenopus larvae. J Histochem Cytochem 44:733-741.

Ohmori H (1985) Mechano-electrical transduction currents in isolated vestibular hair cells of the chick. J Physiol (Lond) 359:189-217.

Oliva C, Cohen IS, Mathias RT (1988) Calculation of time constants for intracellular diffusion in whole cell patch clamp configuration. Biophys J 54:791-799.

Ricci AJ, Fettiplace R (1998) Calcium permeation of the turtle hair cell mechanotransducer channel and its relation to the composition of endolymph. J Physiol (Lond) 506:159-173.

Richardson GP, Russell IJ (1991) Cochlear cultures as a model system for studying aminoglycoside induced ototoxicity. Hear Res 53:293-311. 
Richardson GP, Forge A, Kros CJ, Fleming J, Brown SD, Steel KP (1997) Myosin VIIA is required for aminoglycoside accumulation in cochlear hair cells. J Neurosci 17:9506-9519.

Richardson GP, Forge A, Kros CJ, Marcotti W, Becker D, Williams DS, Thorpe J, Fleming J, Brown SDM, Steel KP (1999) A missense mutation in myosin VIIA prevents aminoglycoside accumulation in early postnatal mouse cochlear hair cells. Ann NY Acad Sci 884:110-124.

Rüsch A, Kros CJ, Richardson GP (1994) Block by amiloride and its derivatives of mechano-electrical transduction in outer hair cells of mouse cochlear cultures. J Physiol (Lond) 474:75-86.

Russell IJ, Kössl M (1992) Sensory transduction and frequency selectivity in the basal turn of the guinea pig cochlea. Philos Trans R Soc Lond B Biol Sci 336:317-324.

Seiler C, Nicolson T (1999) Defective calmodulin-dependent rapid api- cal endocytosis in zebrafish sensory hair cell mutants. J Neurobiol 41:424-433.

Smith C, Neher E (1997) Multiple forms of endocytosis in bovine adrenal chromaffin cells. J Cell Biol 139:885-894.

Thomas P, Lee AK, Wong JG, Almers W (1994) A triggered mechanism retrieves membrane in seconds after $\mathrm{Ca}^{2}+$-stimulated exocytosis in single pituitary cells. J Cell Biol 124:667-675.

Tsien RW, Hess P, McCleskey EW, Rosenberg RL (1987) Calcium channels: mechanisms of selectivity, permeation, and block. Annu Rev Biophys Biophys Chem 16:265-290.

Weiss TF (1996) Cellular biophysics. Cambridge, MA: MIT.

Zhao Y-D, Yamoah EN, Gillespie PG (1996) Regeneration of broken tip links and restoration of mechanical transduction in hair cells. Proc Natl Acad Sci USA 93:15469-15474. 